\title{
EL SUICIDIO EN DURKHEIM, O LA MODERNIDAD DE LA TRISTE FIGURA
}

\author{
EDUARDO BERICAT ALASTUEY \\ Universidad de Málaga
}

\author{
PALABRAS CLAVE ADICIONALES \\ Teoría sociológica, Sociología de la emoción, \\ Cohesión social, Individualismo, Anomia.
}

\section{ADDITIONAL KEYWORDS}

Sociological Theory, Social Cohesion, Sociology of Emotions, Individualism, Anomia.

RESUMEN En este artículo se expone una novedosa interpretación de la tesis elaborada por Durkheim en El Suicidio. Pese a la perspectiva positivista que inspiró su análisis empirico, una atenta consideración del modelo teórico pone en evidencia que el objetivo fundamental de esta tesis era demostrar científicamente la causación social de las emociones. Un detenido análisis de las emociones implicadas en El Suicidio nos sirve, además, para especificar teóricamente, sin las ambigüedades que caracterizan a otras interpretaciones, los conceptos de integración y regulación, que sustentan la tipología de suicidios (altruista/egoísta y fatalista/anómico). La integración se refiere a la dimensión intercomunicativa del orden social, por lo que está vinculada a las emociones de la vergüenza y del orgullo. La regulación se refiere a la dimensión interactiva del orden social, por lo que está vinculada a las emociones del miedo y de la frustración.

\begin{abstract}
From a sociology of emotions perspective, this article proposes a new interpretation of Durkheim' suicide theory. Despite the positivistic approach that inspired his empirical analysis, a detailed review of his theoretical model shows that the main objective of his work was to prove the social causation of emotions. Furthermore, an analysis of the emotions that peryades Durkheim' Suicide is very useful to specify, without ambiguities, the integrative and regulative forms of social cohesion, which are at the base of his suicide typology (altruist/egoist and fatalist/anomic). Integration is related to the intercommunicative dimension of social order, hence the fact that this form of social cohesion was linked to shame and pride emotions. Regulation is related to the interactive dimension of social order, hence the fact that this form was linked to anger and frustration emotions.
\end{abstract}

E-mail: ebericat@uma.es

Revista Internacional de Sociología (RIS)

Tercera Época, nº 28, Enero-Abril, 2001, pp. 69-104. 
RIS

REIISTA INTERNACIONAL DE SOCIOLOGIA

N" 28. Enero-Albril, 2001

EDUARDO BERICAT ALASTUEY

\section{INTRODUCCIÓN}

El presente artículo pretende legitimar y estimular el análisis de las emociones tanto en la teoría como en la investigación sociológica. La sociología, una ciencia que nace con la modernidad, fue arrastrada por el ethos cultural de ésta hacia un positivismo metodológico que parecía implicar, al mismo tiempo, una renuncia a la consideración científica de todo componente subjetivo o contenido de conciencia (ideas, valores y emociones). Si bien esta renuncia apenas fue aplicada al mundo de las ideas, y fue aplicada con cierta benevolencia al universo de los valores, se transformó en pura represión en el caso de las emociones. El propio proyecto de la modernidad contenía, en sí mismo, ese impulso hacia la represión de las emociones. Norbert Elias ha dibujado un proceso de la civilización que se identifica con sucesivos incrementos del autocontrol emocional que ejercen los sujetos sobre sí mismos (Elias, 1993); Albert Hirschman ha revelado el proceso mediante el que la cultura moderna fue transmutando las pasiones en meros intereses (Hirschman, 1999); Adam Smith dedicó su primera gran obra al sentimiento de la simpatía, justificando la continencia emotiva como sustento básico de toda virtud moral (Smith, 1997); Parsons incluyó la neutralidad afectiva, característica de las orientaciones de valor de la cultura moderna, en su esquema de cinco variables-pauta (Parsons, 1982); Scheff, por último, en su teoría sociológica de la vergüenza, muestra cómo el mito fundacional de la modernidad, esto es, el individualismo, no hubiera podido sustentarse sin una profunda y sistemática represión de las emociones (Scheff, 1990).

Un detenido análisis de la teoría de El Suicidio de Durkheim muestra, sin embargo, que ninguna teoría que pretenda explicar o comprender un fenómeno social puede llegar a ser perfectamente inteligible si no se consideran los contenidos emocionales implicados en el fenómeno bajo estudio. Pese a que la estrategia metodológica mediante la que Durkheim elabora su tesis es estrictamente positivista, su obra hace referencia a un amplio, diverso y explícito número de emociones. Este contenido emocional aparece como algo más que mera ilustración o complemento de la tesis, pues constituye, a nuestro entender, parte esencial de la estructura teórica de su obra. Una adecuada comprensión de las emociones vinculadas a cada uno de los tipos de suicidio permite entender, completamente, la cadena de mecanismos causales (Bunge, 1999) que va desde un determinado tipo de estructuración social a un determinado tipo de acto suicida. Cuando en el análisis sociológico se prescinde del eslabón emocional, la conexión entre los fenómenos sociales y las realidades individuales pierde inteligibilidad $\mathrm{y}$, por este motivo, las teorías se convierten en meros análisis de correlación estadística. Esto mismo puede vislumbrarse en un análisis de la tesis weberiana de la ética protestante y el espíritu del capitalismo (Bericat, 2001). Los vínculos causales entre la religión protestante y el ethos capitalista 
se revelan con claridad cuando consideramos las emociones implícitas en las condiciones existenciales fomentadas en los fieles por el credo protestante, en concreto por el dogma de la predestinación (Weber, 1998).

Durkheim no estaba especialmente interesado en el fenómeno del suicidio en sí mismo, sino en la herramienta analítica que las tasas de suicidio le proporcionaban al objeto de, en primer término, mostrar las formas de cohesión social y, en último término, clarificar sociológicamente algunos tipos de malestar característicos de la sociedad moderna. Estos tipos de malestar se corresponden con determinadas emociones o afecciones colectivas que, si bien contribuían en casos excepcionales a la comisión de actos suicidas individuales, tenían una existencia más general, pues afectaban a todos los individuos en virtud de las formas de solidaridad social en la que estuvieran insertos. Podemos sostener, por tanto, que El Suicidio tiene como objetivo fundamental demostrar empíricamente la existencia de determinadas emociones colectivas causadas por los tipos de solidaridad social característicos de la sociedad moderna.

Estas afecciones colectivas aparecen en el análisis de tres ámbitos: el intercomunicativo; el interactivo; y el del orden/caos social (Bericat, 2000b). A la dimensión intercomunicativa de la sociabilidad corresponden los suicidios altruista y egoísta, siendo este último el que caracteriza a la sociedad moderna. En la sociedad tradicional, en aquella sociedad en la que existe un universo simbólico o cultural cerrado, cargado de sentido, las personas pueden suicidarse por vergïenza ante un acto deshonroso o por el orgullo que subyace al cumplimiento de un deber social. En la sociedad moderna, sin embargo, donde la uniformidad de las creencias tradicionales ha dado paso a una multiplicidad equivalente de universos de sentido abiertos, lo que prevalece no es el entusiasmo prototípico que emana de una sólida fusión o identificación comunicativa con el grupo sino, más bien, una pérdida en la intensidad de los valores que lleva directamente a la depresión. La depresión, el desencanto, la melancolía y la tristeza son para Durkheim emociones asociadas a la modernidad, causadas por la disolución de las identidades comunicativas cerradas entre la conciencia individual y la cultura grupal.

A la dimensión interactiva corresponden los suicidios fatalista y anómico, siendo este último el que caracteriza a la sociedad moderna. Cuando la naturaleza o las estructuras de poder social se imponen al individuo de una forma férrea y absoluta, el individuo no puede hacer nada para controlar su entorno y proyectar sobre el mundo su voluntad. En este caso, el miedo radical que el individuo siente ante las imposiciones de la naturaleza o la sociedad paralizan y anulan su voluntad, certificando así la anulación del individuo, un individuo que deja de serlo porque nada puede desear ni nada puede hacer. En el caso contrario, cuando los sujetos viven en un contexto social sin restricciones, cuando las normas sociales que limitan tanto las aspiraciones como los medios disponibles para lograrlas pierden vigencia, esto es, en un estado de anomia, los deseos 
infinitos de los seres humanos les abocan a una existencia de perpetua frustración. Por muchos y valiosos que sean los logros alcanzados por el hombre moderno, en su horizonte siempre existe un nuevo deseo, insatisfecho, que puntea una estela marcada por la decepción.

El orden social, configurado por una adecuada integración de los tres mundos que determinan la existencia de los seres humanos, esto es, el mundo personal, el mundo natural y el mundo social, sustenta la emoción de la confianza. En un estado de orden, las múltiples expectativas que gobiernan las interacciones de los individuos se confirman tanto en la dimensión intercomunicativa como en la interactiva. Al contrario, un estado de caos social, que es algo muy distinto al conflicto existente en el interior de un orden, implica una pérdida de la confianza, una falta absoluta de correspondencia entre las palabras y las cosas, y entre las acciones y la reacciones. La emoción característica de los estados de caos social es la sorpresa, una sorpresa radical producto de la incapacidad para reconocer el mundo y para anticipar sus movimientos, una sorpresa en la que el ser humano es incapaz también de reconocerse a sí mismo. La sociedad moderna, en tanto sociedad que incorpora el cambio como quintaesencia de su naturaleza, genera una dinámica singular en la que orden y caos social coexisten. De ahí que según Durkheim, se genere un nuevo malestar derivado de la sorpresa, de la incertidumbre y de la perplejidad. En suma, un malestar derivado de la endémica falta de confianza que caracteriza a la sociedad moderna. Una ansiedad típica en sociedades de rápidos cambios lineales, y ausente en sociedades de ritmos más pausados o cíclicos.

El diagnóstico emocional de la sociedad moderna desplegado por Durkheim a lo largo de las páginas de El Suicidio, un diagnóstico sin duda negativo en el que reveló malestares asociados a las emociones de la depresión y el desencanto (individualismo), de la frustración y de la decepción (anomia económica), y de la sorpresa y de la ansiedad (anomia social), no implica una absoluta valoración negativa de la modernidad en su conjunto. En la propia polaridad de los tipos de suicidio se hace evidente que, para Durkheim, ambos extremos provocaban aumentos en la tasas de suicidio: una excesiva identificación con el grupo, así como un excesivo aislamiento; un excesivo poder de las normas, así como una excesiva carencia de reglas; una excesiva estabilidad social, así como un ritmo de cambio excesivo.

Ahora bien, pese a esta filosofia del punto medio que mantuvo Durkheim, no cabe duda de que la modernidad y los modernos le evocaban sentimientos de tristeza. Tristeza que es, en el fondo, una forma o expresión del amor. La misma tristeza que provoca el personaje de Don Quijote de la Mancha, un ser también abocado a la depresión, a la frustración y a la ansiedad de la sorpresa. Don Quijote, fusionado e identificado con un universo simbólico que ya nadie compartía, ni siquiera su escudero, se encuentra necesariamente solo y deprimido en el mundo, y salvo en su locura, cuando se imagina acompañado de los 


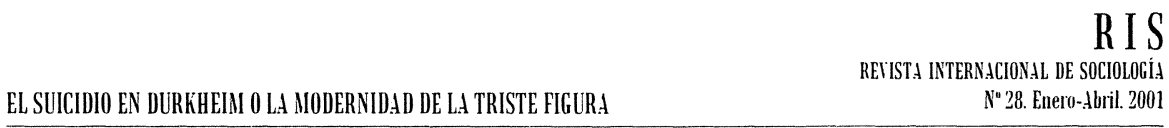

personajes que pueblan aquellas novelas de caballería que obsesivamente había leído, las emociones del orgullo o de la vergüenza no inundan con ilusión sus ojos. Don Quijote, un extraordinario forjador de hazañas, no sólo se enfrenta al ridículo de sus congéneres, sino que se enfrenta también a un mundo en el que esas hazañas resultan ser a la postre literalmente imposibles. Así pues, el Caballero de la Triste Figura también camina por un sendero plagado de frustraciones, un camino en el que las grandes y enloquecidas metas del hidalgo siembran la decepción. Don Quijote, por último, muestra en sus atónitos ojos la radical sorpresa ante un mundo nuevo que no entiende ni obra en consecuencia; es un ser paradigmáticamente perplejo que una y otra vez confunde y se confunde en las cosas, como confundió los molinos con gigantes. Pese a todo, la gran paradoja estriba en que no sabemos muy bien quién nos provoca más tristeza, si el hidalgo caballero o las gentes que de él reían. Una paradoja similar debió de afectar a Durkheim mientras pensaba de consuno modernidad y tradición.

\section{EL MODELO INTENCIONAL DE EL SUICIDIO}

Durkheim, en La división social del trabajo, había intentado resolver algunos aspectos paradójicos de las relaciones entre la persona individual y la solidaridad social. Según sus propias palabras, la cuestión que dio origen a ese estudio fue la siguiente: “¿Cómo es posible que, al mismo tiempo que se hace más autónomo, dependa el individuo más estrechamente de la sociedad? ¿Cómo puede ser a la vez más personal y solidario?" (Durkheim, 1982). La solución que ofreció al problema, suficientemente conocida, consistió en definir dos modos diferentes de solidaridad social, la solidaridad mecánica y la solidaridad orgánica. En la primera, propia de las sociedades tradicionales, los seres humanos estaban unidos en virtud de que compartían un mismo y único conjunto de ideas, creencias y reglas de conducta, esto es, una misma moral, si hemos de hablar en sus propios términos. En la segunda, característica de la sociedad moderna, esta comunión moral se quiebra. Los individuos ya no comparten ni ideas, ni creencias, ni prácticas. Sin embargo, los individuos, al ir especializando sus funciones en el marco de una cada vez mayor división social del trabajo, se necesitan más unos a otros. Esto es, dependen más unos de otros. Así es como Durkheim resolvió la mencionada antinomia.

Pero la pregunta y la preocupación de fondo que dio lugar a La división social del trabajo, incluso tras la resolución técnico-sociológica que ofreció en esta obra, permaneció viva durante todo el desarrollo de su labor intelectual. Durkheim nunca dejó de pensar, como puso de manifiesto en Las formas elementales de la vida religiosa, que sólo una comunidad moral establecía verdaderos lazos de solidaridad entre las personas. Durkheim, podemos decir, había resuelto técnicamente el problema de la solidaridad en las sociedades 
RIS

RETISTA INTERNACIONAL DE SOCIOLOCIA

N" 28, Enero-Abril. 2001

EDUARDO BERICAT ALASTUEI

modernas, pero en su interior seguía latiendo una duda, persistía irresuelto, a su entender, un problema vital. En su opinión, ambas formas de solidaridad no podían ser consideradas, en términos vitales, como equivalentes. En efecto, el orden social puede lograrse con uno o con otro tipo de solidaridad, orgánica o mecánica. Pero el "tipo" de orden logrado difiere en sus consecuencias tanto para los individuos particulares como para la colectividad en su conjunto.

Así que Durkheim, apoyado tanto en sus intuiciones como en sus intenciones originales, siguió investigando. Basta con leer el prólogo que incluyó en la edición de El Suicidio para percibir con claridad cuál era la sensibilidad del autor frente al proceso de modernización. Entre sus típicas argumentaciones metodológicas, reiteradas obsesivamente con el objeto de otorgar con sus trabajos un estatuto científico a la sociología, Durkheim señala que "también se desprenderán de nuestro estudio algunas indicaciones sobre las causas del malestar general ${ }^{l}$ que sufren actualmente las sociedades europeas y sobre los remedios que pueden atenuarlos". "Así, el suicidio, en el estado en que hoy aparece - continúa diciendo el autor- manifiesta, justamente, ser una de las formas en que se traduce la afección colectiva que todos sufrimos, y, por esta razón, nos habrá de ayudar a comprenderla" (Durkheim, 1998). Resulta importante observar que el único asunto material o sustancial citado en el prólogo es, precisamente, este malestar que sufrimos los modernos, esta afección colectiva de la que el suicidio constituye, tan sólo, "una" de sus manifestaciones.

Comprender esta afección colectiva, y más aún, demostrar su existencia y señalar sus causas, constituye el leit-motiv o intención profunda y auténtica del autor (modelo intencional de El Suicidio). El suicidio es tan sólo el instrumento mediante el que podemos alcanzar una conciencia clara y distinta de ese malestar moderno que tanto preocupaba a Durkheim. Estudiando el suicidio también puede demostrarse que las causas de ese malestar son estrictamente sociales. Dicho de otro modo, en El Suicidio se sostiene la tesis de que la sociedad moderna produce malestar. Específicamente, que la organización social del estado de transición que caracteriza al proceso de modernización produce malestar. Un malestar que es general, una afección colectiva que, por serlo, sólo puede tener por causa una realidad social.

\footnotetext{
' La cursiva es nuestra. Como en muchos otros asuntos, Durkheim y Freud coinciden en el diagnóstico general, pero presentan planteamientos radicalmente opuestos. Para Freud, el malestar tenía su origen en las necesidades de coordinación de una sociedad que dejaba estrecho margen para la satisfacción de los impulsos individuales (Freud, 1975). Para Durkheim, el malestar procede del aislamiento, del individualismo y de la anomia en tanto expresión de una deficiente integración social.
} 
El modelo intencional de la investigación, tal y como se indica al final de este párrafo, consta de cuatro elementos fundamentales: a) una determinada realidad social, en concreto, la sociedad moderna; b) genera unas afecciones colectivas, en concreto, ciertos tipos de malestar; c) que sufren en general todos los individuos de esa sociedad; y d) que induce a algunos de ellos a cometer actos suicidas. Desde este modelo se percibe con claridad cómo la división social del trabajo, clave del sistema económico de la sociedad moderna, genera en los individuos, según Durkheim, una insatisfacción o un determinado tipo de malestar, esto es, una determinada estructura emocional. Durkheim, por tanto, está muy interesado, pese a las interpretaciones corrientes que se hacen de El Suicidio, en la causación social de las emociones. De hecho, ¿qué sentido tendría estudiar la sociedad si sus diversas o posibles constituciones no afectaran a los individuos, si no determinaran una específica estructura emocional? Es decir, si no existiesen diferencias entre lo que sienten los miembros de un tipo̊ de sociedad o de otro, el estudio de la sociedad sería irrelevante. Sólo en la medida en que el ser humano es un ser sentiente, capaz de sentirse bien o de sentirse mal, nos preocupan las diferentes constituciones sociales. A un ser humano en absoluto carente de sentimientos, cualquier organización social, incluso la más atroz, le sería en último extremo indiferente. Su intenso interés por la metodología y por la disciplina sociológica ha hecho, sin embargo, que muchos de sus intérpretes pasaran por alto lo que constituye la preocupación fundamental del autor, es decir, la búsqueda de formas de organización social adecuadas a la naturaleza de los seres humanos, formas que les permitan vivir felices o que, al menos, no los condenen irremisiblemente a alguna especie de infierno.

Esquema $\mathrm{n}^{\circ} 1$.

Modelo intencional de El Suicidio

REALIDADES SOCIALES $\longrightarrow$ AFECCIONES COLECTIVAS $\rightarrow$ AFECCIONES INDIVIDUALES $\rightarrow$ ACTOS SUICIDAS

Si bien Durkheim no defendía una vuelta al pasado, y era muy consciente de las ventajas, avances y virtudes de la sociedad moderna, siempre estuvo vivamente preocupado por los acontecimientos sociales que observaba en su entorno. Sobre todo estaba preocupado por el estado de transición de la sociedad tradicional a la sociedad moderna, así como por el riesgo de degradación moral que acompañaba al proceso de modernización. Para él, las realidades sociales eran fundamentalmente realidades morales, así que toda pérdida de moralidad le inspiraba una profunda sospecha. El término "moral", inspirador de su obra, no carecía de cierta ambigüedad, visto al menos desde nuestra perspectiva. Por 
un lado, corresponde a una realidad amplia que incluye ideas, conocimientos, creencias, valores, normas, etc., es decir, corresponde a lo que hoy calificaríamos como universo simbólico o cultura, y él denominó conciencia colectiva. Por otro lado, con el término moral hace referencia a un componente más específico, a los valores, es decir, a esa parte de la cultura destinada prioritariamente a generar consensos que permitan la reglamentación de las demandas conflictivas que proceden de los distintos individuos. Durkheim entendía que estos valores siempre implican una renuncia, un sacrificio de la individualidad en aras de la constitución social (Durkheim, 1993). Sin este sacrifico todo orden social estaría amenazado por conflictos potenciales, no sería un orden social seguro. Los diversos ámbitos de la sociedad, fueran el industrial, el artístico o el científico, le parecían más o menos convenientes, pero nunca del todo necesarios. "Por el contrario, la moral - nos dice- es el mínimum indispensable, lo estrictamente necesario, el pan cotidiano sin el cual las sociedades no pueden vivir" (Durkheim, 1982:60). Podemos ser más o menos ricos, más o menos sabios, o más o menos felices. Pero en sociedad todos y cada uno de los individuos han de ser sujetos morales.

$\mathrm{Si}$, en esencia, la realidad social pudiera identificarse a realidad moral, el modelo expuesto vendría a señalar que los déficits morales pueden tener por consecuencia afecciones sociales. Sin embargo, el pensamiento de Durkheim es algo más complejo, pues aunque concede una importancia sin parangón a las realidades morales y, en general, a la conciencia colectiva, nunca creyó que esta conciencia se nutriera del aire. Es en gran parte producto y expresión de las condiciones sociales de existencia en las que los seres humanos viven, producto y expresión también de sus relaciones sociales y de sus instituciones. Durkheim, de no haber sido ese ferviente sociólogo que era, podría haberse dedicado a lanzar soflamas, aquí y allá, sobre la degradación moral de la sociedad moderna, así como sobre el malestar social del que ella era directo responsable. Hubiera sido un moralista, un filósofo, un intelectual o un reformador social más entre los muchos que poblaron esta época incierta sometida a grandes cambios sociales.

\section{EL MODELO ANALÍTICO}

El gran mérito de Durkheim, la genialidad que lo distingue de todos los demás, estriba en haber invertido los eslabones del modelo intencional antes descrito, modelo que constituía sin duda un lugar común de la época. Hablar directamente del malestar de la época, de las emociones negativas que el proceso modernizador estaba causando en la gente, le hubiera parecido a él pura especulación filosófica. Estaba empeñado, tal y como señaló en la primera frase del prefacio a la primera edición de La división social del trabajo, en construir la 
ciencia de la moral: "Este libro es, ante todo, un esfuerzo para tratar los hechos de la vida moral con arreglo a los métodos de las ciencias positivas" (Durkheim, 1982:39). Por tanto, su intención de resaltar las afecciones colectivas de la modernidad no podía llevarla a cabo de un modo directo y explícito, sino que tendría que satisfacerla surcando senderos un poco más tortuosos e indirectos. El Suicidio es el resultado de esta inversión del modelo intencional, inversión que instituye el modelo analitico que inspiró el diseño metodológico de la investigación, así como el proceso expositivo o narrativo de esta obra. De este modelo se pueden ofrecer dos representaciones alternativas pero compatibles.

Esquema $\mathrm{n}^{0} 2$.

Modelo analítico $A$

SUICIDIO $\rightarrow$ AFECCIONES INDIVIDUALES $\rightarrow$ AFECCIONES COLECTIVAS $\rightarrow$ REALIDADES SOCIALES

Esquema $\mathrm{n}^{\circ} 3$.

Modelo analítico $B$

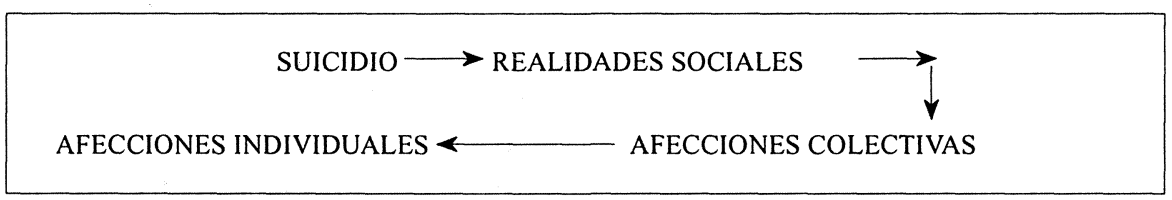

Desde una orientación positivista, animado por la voluntad de tratar a los hechos sociales como cosas, es obvio que Durkheim no podía enfrentarse directamente con las emociones, pues éstas constituyen el contenido de conciencia más subjetivo, lábil y difícil de determinar. Si explícitamente renuncia a considerar los motivos del suicida por la imposibilidad de conocerlos con certeza, con mayor razón habría de renunciar a cualquier análisis emocional directo. Cómo saber, nos dice, "cuál es el móvil que ha determinado al agente, y si al tomar su resolución, era la misma muerte lo que deseaba o se proponía otro fin. La intención es una cosa demasiado íntima, para que pueda ser apreciada desde fuera y por aproximaciones groseras. Se sustrae a la misma observación interior" (Durkheim, 1998:4). Así pues, el camino que está decidido a emprender es otro. Tal y como muestra el modelo A, tanto las afecciones individuales como 
RIS

RETISTA INTERNACIONAL DE SOCIOLOGIS

No 28. Enero-dbril. 2001

EDUARDO BERICAT ALASTUEY

las colectivas quedan recluidas en una especie de caja negra, estableciéndose un análisis de correlación entre variables externas, observables y mensurables. Por un lado, los "actos suicidas", por otro, determinados "rasgos de la realidad social". Recordando su definición del suicidio, "todo caso de muerte que resulte, directa o indirectamente, de un acto, positivo o negativo, realizado por la víctima misma, sabiendo ella que debía producir este resultado" (Durkheim, 1998:5), es obvio que el autor no escapa del todo a la necesidad de incluir aspectos cognitivos de la subjetividad del agente, pues éste debía "saber" que tal resultado fatal habría de producirse. Sin embargo, utilizando el acto suicida como variable, Durkheim establece un modo de escapar al laberinto al que le hubiese conducido la consideración directa de las intenciones y de las emociones del agente.

Si el modelo intencional era deductivo, el analítico es inductivo. Así expone Durkheim su proyecto: "Sin preocuparnos de saber bajo qué forma pueden traducirse en los sujetos particulares las causas productoras del suicidio, vamos directamente a tratar de determinar estas causas. Para ello, dejando a un lado, por decirlo así, al individuo en cuanto individuo, a sus motivos, a sus ideas, nos preguntaremos inmediatamente cuáles son los estados de los diferentes medios sociales (confesiones religiosas, familia, sociedad, política, grupos profesionales, etc.) que determinan las variaciones del suicidio. Sólo después de esto, volviendo a los sujetos, investigaremos cómo estas causas generales se individualizan para producir los efectos homicidas que implican" (Durkheim, 1998: 139-40). Ahora bien, una vez establecidas las correlaciones empíricas, es necesario determinar qué rasgos de cada estado social asociado a altas o bajas tasas de suicidio son los causantes de las variaciones en las tasas de suicidios. La inicial localización de diversos estados sociales facilita la tarea, aunque, como es obvio, no la resuelve completamente. El análisis estadístico de "caja negra" limita las posibilidades de argumentación, pudiendo corroborar o refutar hasta cierto grado algunas de las hipótesis, pero no alcanza a determinar inequívocamente la causa. Como indica el propio Durkheim, es necesario abrir la caja negra y mirar en su interior. Y aquí volvemos a toparnos con las ideas, con los valores y con los afectos, esto es, con los contenidos básicos de la conciencia y de la cultura. Descubiertas las relaciones empíricas entre actos suicidas y realidad social, queda la tarea de hacerlas inteligibles. Estamos, pues, ante el mismo problema que tuvo que afrontar Weber tras descubrir que la adscripción religiosa estaba empíricamente asociada con el desarrollo económico (Bericat, 2001). Un acto suicida, como cualquier acto de voluntad, no puede estar provocado por una idea o por un valor sin la presencia de una emoción. Es necesario, por tanto, analizar las condiciones de conciencia conectadas a cada medio social. Durkheim llevó el análisis empírico de variables mucho más lejos que Weber, pero Weber llevó el análisis cualitativo mucho más lejos que Durkheim (Bericat, 1998). Weber infirió las condiciones de la conciencia del análisis de informaciones empíricas 
de carácter comunicativo (Weber, 1998). Durkheim realizó inferencias emocionales recurriendo a una especie de inducción teorética ${ }^{2}$ soportada sobre un pormenorizado análisis de una variable cuantitativa (número de suicidios) y de diversas variables nominales (adscripción religiosa, estado civil, etc).

En cualquier caso, como decimos, Durkheim también hubo de enfrentarse a la tarea de otorgar sentido e inteligibilidad a las correlaciones descubiertas entre los hechos objetivos, esto es, por un lado el número de "actos suicidas" y, por otro, diferentes "rasgos de los estados sociales" en los que se hallaba inmerso el individuo. Según el modelo metodológico $\mathrm{B}$, que sigue más de cerca la línea expositiva del libro de Durkheim, tras localizar las correlaciones hubo de determinar qué afecciones colectivas, o climas emocionales, tal como diríamos hoy, estaban asociados a esos estados sociales y podrían ser causantes de los actos suicidas. Hacia el final de la obra, Durkheim se enfrenta también con las emociones individuales que pudieran estar detrás de los diversos tipos de suicidio. Sin duda, Durkheim dedica menos esfuerzo y aplica menos rigor a la clasificación morfológica de los suicidios, que es una clasificación de las emociones asociadas a cada tipo, que a la clasificación etiológica, en la que se ofrece una clasificación social de las causas del suicidio ${ }^{3}$. A pesar de esto, Durkheim no sólo dedica un capítulo entero de su obra a los estados emocionales del individuo asociados a cada tipo de suicidio, sino que, a lo largo de los cuatro capítulos que dedica a los tipos de suicidio, la búsqueda de las emociones colectivas subyacentes no deja de ser en ningún momento un objetivo clave. Como veremos más adelante, sin esta determinación emocional los modelos teóricos subyacentes a cada tipo de suicidio carecerían de inteligibilidad. En suma, el análisis emocional, si bien hasta cierto punto soterrado o paspuesto, constituía parte esencial del desenvolvimiento teórico de la obra. Un análisis de variable, por sí mismo, aunque ayudaba a establecer las conexiones necesarias, no era suficiente para cerrar los modelos teóricos que finalmente emergieron de la investigación.

\footnotetext{
${ }^{2}$ Esta inducción teorética comparte algunos rasgos metodológicos con la inducción analítica de F. Znaniecki. Ambas parten de minuciosos análisis empiricos con la finalidad explicita de descubrir modelos teóricos que den cuenta de la realidad observada. Sin embargo, mientras la inducción analítica utiliza el estudio cualitativo de casos, y la comparación entre casos, como medio de estimular los descubrimientos teóricos, la inducción teorética utiliza el análisis de variable para depurar, definir y comparar casos.

${ }^{3}$ El hecho de que a la "clasificación emocional" de los tipos de suicidio la denomine "clasificación morfológica" es sintomático del intento general, en la sociología clásica positivista, de ocultar hasta cierto punto las referencias emocionales directas (Scheff, 1990).
} 
El. autor refiere en muchas ocasiones, explícita o implícitamente, las afecciones colectivas o el humor colectivo asociado a ciertos estados sociales. $\mathrm{Y}$ aquí podría hacerse una objeción similar a la que habitualmente se hace a su concepto de conciencia colectiva ¿Existen tales humores o afecciones, tales climas, tales emociones? La respuesta exige algunos matices, pero creo que Durkheim apuntaba en la buena dirección. En primer lugar, podemos hablar de emociones colectivas en tanto están causadas por factores sociales. Así, todos los individuos que compartan un mismo estado social que contenga un factor inductor de algún componente emocional, sentirán en alguna medida esa misma emoción. En un sentido tanto etiológico como fenoménico podemos calificar como sociales a este tipo de emociones. Como es obvio, esto no significa que exista una entidad supraindividual que realmente "sienta" esa emoción. Es decir, los únicos seres que sienten son los seres humanos individuales. Sin embargo, hay algo más, algo que no es tan obvio y evidente, pero que emerge del hecho de que todos los miembros de un grupo estén, en alguna medida, afectados por un mismo componente emocional. Las emociones no sólo yacen en el interior de los sujetos, sino que también circulan por las intercomunicaciones que se producen entre los sujetos. Dado que la comunicación, finalmente, se materializa en tanto realidad externa, y dado que esa realidad porta rasgos emocionales, podemos decir que la comunicación social, cargada afectivamente, puede reinsertarse en los sujetos individuales (Bericat, 1999). En este estricto sentido, podemos afirmar que existen emociones colectivas o sociales. En suma, si como nosotros pensamos, en la comunicación existen emociones, de la misma manera que existen ideas y valores, podemos hablar de climas emocionales $o$ de emociones colectivas sin referirnos a una entelequia o una realidad meramente nominal.

Lo que Durkheim buscaba eran esas corrientes difusas de sentimiento asociadas a los estados sociales de la modernidad. En términos de comunicación social, señala que "sólo cuando esos sentimientos adquieren una fuerza excepcional, es cuando absorben lo bastante la atención pública para ser percibidos en su conjunto, coordinados y sistematizados, y llegan entonces a formar la base de doctrinas completas de la vida"4 (Durkheim, 98:413). Estas emociones colectivas, sentidas también por los individuos no son, sin embargo, las que se derivan de rasgos particulares y específicos de su experiencia vital y biográfica, las que proceden de situaciones y contextos estrictamente individuales. No son, en suma, las miles de emociones concretas, a veces

\footnotetext{
${ }^{4}$ Durkheim menciona aquí a modo de ejemplo las doctrinas de Epicuro, Zenón, Schopenhauer y Hartmann, doctrinas todas ellas pesimistas y que, como veremos más adelante, tienen mucha relación con la filosofia de la felicidad que subyace a su concepto de anomia.
} 
instantáneas, casi siempre efimeras, que cada uno podemos sentir a lo largo de un solo día de nuestra existencia. Son emociones vinculadas a la naturaleza del estado social en el que vivimos, emociones que perduran tanto como los estados sociales de las que son efecto, emociones que, por este motivo, nos afectan en general a todos los miembros de una determinada sociedad. Emociones, y este es un punto dificil de sobrevalorar a la hora de comprender íntimamente la obra de Durkheim, que indican la salud de ese estado social, que cumplen una función de señal (Hochschild, 1983).

Aquí es, precisamente, donde el crecimiento de las tasas de suicidio adquiere su verdadero sentido y trascendencia para el estudio social. "Es muy posible, y hasta verosímil - dice Durkheim-, que el movimiento ascensional de los suicidios tenga por origen un estado patológico que acompañe a posteriori a la marcha de la civilización, pero sin ser su condición necesaria. No permite otra hipótesis la rapidez con que ha aumentado. En efecto, en menos de cincuenta años, se ha triplicado, cuadruplicado, hasta quintuplicado, según los países. Por otro lado, sabemos que afectan a lo que hay de más inveterado en la constitución de las sociedades, puesto que expresan su humor ; y el humor de los pueblos, como el de los individuos, refleja el estado del organismo en lo que tiene de más fundamental". "Los cambios que impone la estadística de los suicidios contemporáneos no pueden, pues, ser normales. Sin saber con precisión en qué consisten, se puede afirmar, por adelantado, que resultan, no de una evolución regular, sino de una conmoción enfermiza que ha podido muy bien desarraigar las instituciones del pasado, sin poner nada en su lugar; porque la obra de los siglos no se rehace en sólo unos años" (Durkheim, 98:412-13). Siguiendo esta línea argumental, es bastante evidente que el suicidio sirve de indicador de determinados estados afectivos que, a su vez, sirven de indicador de determinadas patologías sociales, objetivo último de la obra de Durkheim. Bien sigamos la línea marcada en su modelo intencional, bien la marcada en su modelo analítico, siempre encontraremos las emociones en un punto intermedio pero también en un punto final.

\footnotetext{
${ }^{5}$ Esta "función de señal", característica de las emociones, fue originalmente puesta de manifiesto por S. Freud al tratar la angustia. La diferencia entre Freud y Durkheim es que el primero relaciona la emoción con el estado individual de salud, mientras que el segundo la relaciona con el estado social.

'La cursiva es nuestra.

${ }^{7}$ La cursiva es nuestra.
} 
RIS

RETISTA INTERNACIONAL DE SOCIOLOGI.

N" 28. Enero-Abril. 2001

EDUARDO BERICAT ALASTUEY

El suicidio nunca constituyó para Durkheim el objetivo final de su estudio, sino la vía de acceso positivista que le permitiría analizar, localizar y determinar científicamente las afecciones colectivas derivadas de una determinada patología social asociada con la modernidad.

\section{INDIVIDUALISMO Y DEPRESIÓN}

Para entender el suicidio egoista quizás sea oportuno intentar comprender, previamente, el suicidio altruista. Ambos están asociados al grado de individuación, excesivo o insuficiente, que caracteriza a un determinado medio social. Cuando la cohesión social es muy alta, tal como ocurre en las sociedades tradicionales, los suicidios altruistas se incrementan. Cuando la cohesión social es muy baja, lo que acontece en las sociedades modernas, los suicidios egoístas aumentan. Sin embargo, es necesario precisar que para Durkheim existen dos dimensiones diferentes que pueden contribuir a la cohesión social, una es la integración, la otra la regulación (Besnard, 1998) (Rodríguez Ibáñez, 1999). El suicidio egoísta o el altruista dependen, exclusivamente, del grado de cohesión social alcanzado por efecto de la dimensión integradora. Y aunque en la exposición de casos las dos dimensiones aparecen muchas veces confundidas, es muy importante llegar a comprender la distinta naturaleza de cada una de ellas. Para nosotros, el factor integrativo de la cohesión social está vinculado a la dimensión intercomunicativa del orden social: Como veremos más adelante, el factor regulativo de la cohesión social está vinculado a la dimensión interactiva del orden social (Bericat, 2000b).

La integración de las sociedades está vinculada, por tanto, a la conciencia individual y colectiva, a la cultura, al universo simbólico de los seres humanos o a sus procesos y contenidos de comunicación. Todos estos términos, cultura, conciencia y comunicación, han de tomarse como referentes de una realidad esencialmente idéntica. Las ideas, las creencias, los valores, las emociones y las normas ${ }^{8}$ son algunos de los fenómenos que pertenecen a esta dimensión de la realidad social. Durkheim parte del supuesto de que una sociedad estará más integrada cuanto más sólida e intensa sea su conciencia colectiva. Esto significa mayor número de creencias, de valores y de sentimientos aceptados, impuestos o interiorizados por mayor número de miembros de ese grupo social. La integración, a los ojos de Durkheim, es cuestión de grado, pero puede medirse

${ }^{8}$ Sobre el ambiguo estatuto de la "normas sociales", que algunos sociólogos incluyen en el ámbito de la cultura sin ofrecer las necesarias matizaciones, ver los argumentos que se exponen más adelante. 
por los dos elementos señalados, es decir, por la parte, mayor o menor, de cultura que se comparte, y por el número de miembros, mayor o menor, que la comparte. Estas dos condiciones extensivas se yuxtaponen para determinar la intensidad o fortaleza de los vínculos culturales. Si los individuos comparten tan sólo algunas creencias y valores, su universo simbólico será básicamente un universo abierto en el que el libre examen o la conciencia individual determinará en mucha mayor medida sus propios contenidos que, de este modo, acabarán diversificándose. Alternativamente, si son pocos los individuos que comparten un gran numero de creencias y de valores, tampoco nos encontraremos ante un universo simbólico sólido y cerrado, pues siempre el ser humano encontrará en el seno de su medio social otras posibles referencias culturales. Dicho en una terminología más actual, en ambos casos se incrementan las probabilidades que tiene el individuo de enfrentarse a una crisis de sentido (Berger y Luckmann, 1997). Para Durkheim el sentido se configura en tanto cierre social de la dimensión intercomunicativa.

Como hemos dicho, de entre los tres elementos básicos de la cultura (cognitivos, valorativos y emotivos), Durkheim parece otorgar un mayor estatuto al orden moral, aunque, como también hemos mencionado, equipara muchas veces realidad moral y realidad cultural. Desde la consideración de toda su obra, sin duda, los componentes valorativos y emotivos son los que juegan un papel clave en la naturaleza integrativa de la cohesión social. Por el contrario, los cognitivos, asociados a la inteligencia, a la ciencia y al libre examen, parecen actuar como disolventes de los cierres de sentido. Dado que la integración del grupo, así como la integración de un individuo en el grupo, constituye un problema de identidad social, es necesario ver qué efectos pueden tener los diferentes elementos de la cultura en la constitución de esa identidad social. Parece obvio que el hecho de que dos personas compartan una misma "idea", esto es, un elemento cognitivo, puede contribuir a su identificación mutua. Pero como la ideas no tienen por referencia a la persona, sino que pretenden representar algún aspecto de la realidad exterior, la comunión de ideas es incapaz de producir una identificación íntima entre dos sujetos. Los valores, por otro lado, al expresar los criterios de preferibilidad, esto es, los criterios que definen lo bueno y lo malo, el bien y el mal, y estar generados en el marco de la interacciones sociales, pueden dar lugar a una identificación social más íntima. Sin embargo, como los valores tampoco tienen por referencia directa a las personas, sino a la realidad social en la que habitan, una realidad externa al yo, son incapaces de promover una total implicación de las conciencias individuales con la sociedad. Si bien es cierto que los valores, debido a que su naturaleza es eminentemente social, contribuyen en mayor medida a la integración colectiva (Parsons, 1982), una íntima fusión de las conciencias sólo puede darse en el marco de una comunidad emocional. Como las emociones refieren directamente al sí mismo, a la realidad interior de la personas, y como 
RIS

REIISTA INTERNACIONAL DE SOCIOLOCIA

N" 28. Enero-Abril. 2001

EDUARDO BERICAT ALASTUEI

las emociones señalan la relevancia de la situación exterior para el sujeto, en la medida que dos personas compartan unos mismos sentimientos, ante una determinada situación, podrán considerarse una misma persona. De ahí que la etimología del término intimidad aluda al hecho de compartir idénticos miedos. Si sentimos lo mismo, bien sea en la conmoción, bien sea en la compasión, alcanzaremos el más alto grado de identidad social. Si me defino como persona por aquello que siento, tú serás, como individuo, idéntico a mí en la medida que sientas lo mismo que yo. Desde nuestra perspectiva, este juego de la identidad, fraguado con los elementos de la cultura, de la conciencia o de la comunicación es la esencia que opera en la dimensión integrativa de la cohesión social.

Creemos también que esta es la idea matriz de Durkheim, tal y como fue definitiva y explícitamente expuesta en su última gran obra, Las formas elementales de la vida religiosa. De esta obra queremos destacar su libro tercero, dedicado al análisis de las principales actitudes rituales. En él pone de manifiesto que la esencia de lo sagrado, identificable con el orden moral en tanto segunda naturaleza humana, se comprende en su forma pura en las prácticas rituales de las religiones totémicas. Analizando el rito sacrificial de la tribu aborigen de los arunta, conocido por el nombre de intichiuma, Durkheim cree haber descubierto la clave de la integración social. Todo rito sacrificial, y por extensión cualquier rito, se compone de dos actos, un acto de comunión y un acto de oblación o de renuncia. El primero crea un vínculo entre los miembros del grupo, los hace partícipes de una naturaleza común, que en este caso es la naturaleza propia del tótem particular del grupo. Mediante el segundo se expresa la renuncia del yo individual, pues esto es en verdad lo que viene a ser sacrificado en el rito. En la práctica ritual todos los miembros del grupo comparten un mismo foco de atención, así como unos mismos sentimientos. Focalizando su atención sobre lo sagrado, expresión de los valores más queridos del grupo, y por tanto del grupo mismo en tanto orden moral, y sintiendo lo mismo que el resto de los miembros del grupo, el individuo modifica radicalmente su espíritu en el sentido de orientarlo a la realidad grupal. En la conciencia se produce, por expresarlo de algún modo, un milagroso y radical olvido de sí. Sólo en los ritos, de acuerdo con Durkheim, los individuos son capaces de experimentar realmente la fuerza de lo social en su conciencia. Pero esta fuerza, para ser experimentada en tanto fuerza eficiente, y no en tanto mera metáfora de lo social, ha de ser experimentada como emoción. Sólo la conmoción colectiva sentida en el rito logra sacar al individuo de sus cuitas cotidianas y seculares, de sus intereses privados y particulares, profanos, para ponerlo en comunicación con lo sagrado y renovar así la energía social. Sólo esta energía trasmitida en la conmoción ritual consigue hacer efectivo el verdadero sacrificio, esto es, la renuncia del egoísmo individual necesaria para el cumplimiento de los valores sociales (Durkheim, 1993). 


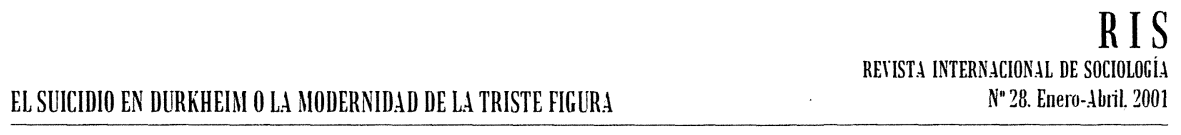

Este contexto, propio de la sociedad tradicional, en el que los valores vienen acompañados de una gran carga emocional, y donde el sentido de la existencia está clausurado por un consenso intercomunicativo hermético, es el caldo de cultivo adecuado para el suicidio altruista. Una individuación insuficiente conlleva, de una parte, una pérdida de valor del individuo y un descenso en el precio de su vida. De otra parte, la íntima identificación del individuo con los valores colectivos hace que cualquier transgresión de los mismos, reduzca aún más su valor. Con tanta intensidad vive el individuo en la mente de los otros, tanto depende nuestro valor de la correspondencia de nuestras acciones con el orden moral que cierra el sentido de la existencia del grupo que, primero, cualquier desviación puede privar al individuo de las razones necesarias para seguir viviendo o, segundo, cualquier cumplimiento del deber moral, en tanto valor, proporciona al individuo razones para matarse. Y esto explica que en todos los actos suicidas de este tipo operen las emociones de la vergüeñza o del orgullo, que son para Scheff las emociones sociales por antonomasia (Scheff, 1990).

Durkheim no sistematiza la influencia de estas dos emociones, aunque se refiere directa o indirectamente a ellas en muchas partes del texto. Por ejemplo: "los guerreros daneses, consideraban como una vergüenza morir en su cama, de vejez o enfermedad, y se suicidaban para escapar a esta ignominia"; "Si el hombre se mata, no es porque se arrogue el derecho de hacerlo, sino porque cree que es su deber, cosa bien distinta. Si falta a esta obligación, se les castiga con el deshonor y también, lo más a menudo, con penas religiosas"; "Si persiste en vivir pierde la estimación de las gentes"; "En Polinesia, basta muy a menudo una ligera ofensa para determinar al hombre al suicidio"; "lo que se hace en un caso para escapar a la deshonra se hace en el otro para conquistar mayor estima" (Durkheim, 1998:225-231). Sea en el caso de los soldados, "que prefieren la muerte a la humillación de la derrota", sea en el de aquéllos "que se matan para evitar una vergüenza a su familia", la causa social que produce las emociones que finalmente llevan a la muerte es la identidad moral entre el individuo y el grupo. Esto explica que en este tipo de actos suicidas estén presentes también la esperanza de lograr la estima, o el miedo de caer en la vergüenza. En cualquier caso, para que exista esperanza o miedo deben existir un valor o un antivalor, algo sentido intensamente como bueno y deseable, o algo sentido intensamente como malo e indeseable. En suma, hacen falta metas o fines sustentados colectivamente a los que tienda el individuo, esto es, valores. De ahí que Durkheim, hablando de la fenomenología emocional de este tipo de suicidio, hable de entusiasmo, aunque "este entusiasmo mismo es unas veces alegre, y otras sombrío, según que la muerte sea concebida como un medio de unirse a una divinidad bien amada o como un sacrifico expiatorio". En cualquier caso, "el suicidio altruista, como tiene por origen un sentimiento violento, no ocurre sin cierto despliegue de energía" (Durkheim, 1998:309). Estos actos suicidas, eminentemente 
activos, siempre están impulsados por una intensa carga emocional, por la vergüenza o el orgullo que procede de la identidad de conciencia entre el individuo y el grupo.

Muy diferentes, sin embargo, son la carga y el contenido emocional que acompañan y causan el suicidio egoísta, cometido en el marco social de una individuación excesiva. Este tipo de suicido, en primer lugar, carece de esa intensa energía y vitalidad característica del suicidio altruista. En segundo lugar, la apatia, la tristeza, la desesperanza, el desencanto, la melancolia y la depresión resultan ser sus emociones características. No es un suicidio activo, sino un suicidio depresivo, uno en el que el individuo no encuentra razones para vivir ni es capaz de encontrar ningún sentido en la vida. Nada o casi nada le ata a la vida, y podría decirse que muere por falta de estímulos con suficiente valor, muere en un puro aflojamiento de la voluntad, sumido en un profundo y abismal vacío. Así es como Durkheim define emocionalmente este suicidio: "Esta pereza por la acción, este apartamiento melancólico"; "sabiendo que no puede esperar nada de otro, no pide ya nada, completamente dispuesto,..., a deshacerse de una existencia que no tiene razón de ser"; "lo que distingue al egoísta que se mata es una depresión general que se manifiesta, por una languidez melancólica, o por la indiferencia epicúrea", por un "debilitamiento de la voluntad de vivir" (Durkheim, 1998:306-9). Pero este debilitamiento de la voluntad, que en algunos individuos llega al extremo del suicidio, afecta a todos los miembros de una sociedad desintegrada, constituye parte de su más auténtico humor colectivo o clima emocional: "hay un humor colectivo, como hay un humor individual, que inclina a los pueblos a la tristeza o a la alegría"; "así se forman corrientes de depresión y de desencanto que no emanan de ningún individuo particular, pero que expresan el estado de desintegración en que se encuentra la sociedad. Lo que traducen es el relajamiento de las bases sociales, una especie de astenia colectiva, de malestar social, como la tristeza individual, que cuando es crónica traduce a su manera el mal estado orgánico del individuo"; "Su sufrimiento [el de la sociedad] se hace el sufrimiento de ellos [el de los individuos]. Por ser el todo, el mal de que se resiente se trasmite a las partes de que está formada"; "Entonces aparecen esos sistemas metafísicos y religiosos que, reduciendo a fórmulas esos sentimientos obscuros, vienen a demostrar a los hombres que la vida no tiene sentido"; "Por individualizado que cada uno esté, queda siempre algo colectivo; la depresión y la melancolía que resultan de esta individuación exagerada. Se comulga con la tristeza, cuando no hay otro ideal común" (Durkheim, 1998: 220-221). En suma, quien dice individualismo, dice depresión.

Los sentimientos de depresión, la apatía, la tristeza, la desesperanza, el desencanto, la desgana de vivir constituyen, por tanto, un rasgo propio de la sociedad moderna o, al menos, de las sociedades en proceso de modernización. El sentimiento de depresión está determinado por causas sociales, y constituye, 
a juicio de Durkheim, una de las caras de la triste figura de la modernidad. Pero, ¿qué puede hacer inteligible las conexiones entre cohesión social, en su vertiente integrativa, y el sentimiento de depresión? Dos aproximaciones teóricas, fundadas en el propio discurso durkheimiano, pueden arrojar cierta luz a la caja negra interpuesta en las correlaciones detectadas entre realidad social y suicidios egoístas.

En primer término, basta con recordar la naturaleza del contexto social que caracteriza al suicidio altruista para comprender las fuentes de la depresión. Un universo simbólico cerrado, y por tanto intenso, contiene un orden moral o valorativo que penetra íntimamente en la conciencia de los individuos. Estos sujetos, inmersos en un completa clausura del sentido, sienten vivamente la tensión que les proporcionan los valores del grupo. Siendo esto así, como ya habíamos apuntado, la esperanza y el miedo, la vergüenza y el orgullo, alimentan las energías y los esfuerzos de sus vidas. Pero cuando la fortaleza de los valores disminuye, la tensión también disminuye, y los seres humanos pierden gran parte de su motivación. Las cosas que valen, las metas por las cuales merece la pena esforzarse, no se presentan ahora con un perfil tan claro, y eso hace que tanto la alegría como la tristeza pierdan carga emocional. Como los deseos que exceden las necesidades meramente biológicas del ser humano son puestos por la sociedad, una reducción y debilitamiento de sus consensos simbólicos, que determinan la fuerza del valor, corre en paralelo a una debilitamiento de la mayor parte de los deseos humanos, que son de origen social ¿Qué valor tiene vencer en una competición atlética si el estadio está completamente vacío?, ¿cómo vamos a realizar esfuerzos si nadie los valora? Entender que la mayor parte de los deseos de los seres humanos son deseos sociales, esto es, no biológicos, equivale a entender la depresión que emerge cuando el orden y la comunidad moral se debilitan. La falta de identidad del individuo con el orden intercomunicativo creado por la sociedad equivale a la ausencia de valor, y así al vaciado de los deseos. Casi todo pierde la fuerza viva del interés, que parece individual, pero que tiene fundamento social. Fuera de este universo simbólico, los intereses personales, carentes del refuerzo social, dejan de interesarnos, y así caemos en este nihilismo solitario donde la tensión y el esfuerzo se nos antojan carentes de sentido. Es por esto que Durkheim, al estudiar la sociedad religiosa, señala como causa de este sentimiento mórbido de depresión, no al libre examen, ni a la ciencia, sino a la decadencia de las creencias tradicionales y al individualismo moral en que esa decadencia desemboca (Durkheim, 1998:162). "La influencia bienhechora de la religión no se debe a la naturaleza especial de las concepciones religiosas. Si protege al hombre del deseo de destruirse, no es porque le prescriba con argumentos sui géneris, el respeto de su persona; es porque constituye sociedad. Y lo que constituye esta sociedad es la existencia de un número de creencias y prácticas comunes a todos los fieles, tradicionales $\mathrm{y}$, en consecuencia, obligatorias. Cuanto más numerosos y fuertes son estos 
RIS

REISTTA INTERNACIONAL DE SOCIOLOGIA

N" 28. Enero-.tbril. 2001

EDUARDO BERICAT ALASTUEY

estados colectivos, más fuertemente integrada está la comunidad religiosa y más virtud preservativa tiene" (Durkheim, 1998:164).

En segundo término, el debilitamiento de la comunidad moral, asociado al debilitamiento de la identidad emocional con los otros, ha de implicar un paralelo debilitamiento del altruismo. Esto es, un orden moral siempre conlleva, según dijimos, el olvido del yo, así como la disposición individual al sacrifico en función, bien de necesidades generales de la comunidad, bien de necesidades particulares de otras personas concretas. Sin esta comunidad moral los individuos sólo pueden vincularse entre sí por los procesos de intercambio y reciprocidad de bienes y servicios, vínculos que presuponen una inicial y radical separación entre los sujetos. El "otro" sólo se desprenderá de un bien y sólo me prestará un servicio en la medida que yo esté dispuesto, intencional y materialmente, a prestarle un servicio o a entregarle un bien de equivalente valor. Las cosas se intercambian por las cosas, de ahí que este modelo de intercambio no requiera una íntima implicación de los sujetos, más bien al contrario. Lo que aquí importa son los precios de los respectivos objetos, no el valor de las respectivas personas. La circulación de dones, o entregas voluntarias en función de este valor personal, se detiene o se atrofia, así que nadie entrega ni recibe nada de nadie voluntariamente. En el seno de un grupo en el que existe una fuerte identidad entre los miembros, que, como ya hemos dicho, implica una comunión de sentimientos, las entregas voluntarias al otro constituyen la norma de este intercambio especial, no de bienes, sino de dones (Godelier, 1998). Esto es precisamente lo que sucede en la sociedad familiar, y lo que sucede en mayor medida, como bien demuestra estadísticamente Durkheim, en la relación familiar de padres e hijos, no tanto en la conyugal de esposa y esposo. La densidad familiar genera una comunidad de sentimientos en el que las entregas voluntarias, por este mismo motivo, no se conciben como pérdidas individuales. $Y$ esto es precisamente lo que evita los sentimientos de depresión. Para Kemper el sentimiento de depresión es provocado por lo que él denomina una carencia de "status", esto es, por una falta de recompensas ofrecidas "voluntariamente" por los otros, sean recompensas materiales, sean de reconocimiento o de afecto (Kemper, 1978). Tristeza o depresión que, según Freud, es provocada por la pérdida del otro, por la ausencia de otros implicados emocionalmente con el yo. De ahí que Durkheim asocie el suicido egoísta con el menor número de miembros de la familia, en tanto expresión de un descenso de la densidad familiar asociada a una fuerte identificación grupal constituida sobre una amalgama de recuerdos y de sentimientos comunes.

En fin, son estos sentimientos de identificación los que establecen una comunicación más densa e íntima entre la subjetividad de las personas $\mathrm{y}$, por tanto, los que procuran una intensidad mayor a la vida colectiva. Por este motivo, cualquier conmoción política, como Durkheim demuestra con la exposición de varios ejemplos históricos, reduce las tasas de suicidio. En situaciones de 
crisis social, sean revoluciones, crisis electorales o grandes guerras se agitan las pasiones políticas y se enervan los sentimientos colectivos. Los miembros de esta unidad política sienten lo mismo frente a una situación amenazadora, y esta identidad de los sentimientos, mayor cuanto más intensa, integra la sociedad y reduce la individuación. Suponen siempre una fortalecimiento de los valores colectivos (primer factor de explicativo), así como una regeneración del altruismo o de la lógica del don (segundo factor explicativo). De lo que a Durkheim no le cabe la menor duda es que, primero, son los procesos de lucha, de resistencia o de oposición los que intensifican la identidad social. Y segundo, que si esta identidad no viene acompañada de emociones, no es una verdadera identidad social y, por tanto, no se produce el esperado descenso de la tasa de suicidios, no se consigue arrancar en cierto grado a los individuos de su solitaria depresión (Durkheim, 1998:11-13), que es la endémica enfermedad emocional, a duras penas disimulada, que se manifiesta en la triste figura "de los individuos modernos.

\section{ANOMIA Y FRUSTRACIÓN}

Para entender el suicidio anómico también nos parece oportuno comenzar comprendiendo el suicidio fatalista. Sin embargo, aquí nos encontramos con una dificultad añadida, pues, como es sobradamente conocido, Durkheim tan sólo dedicó a este tipo de suicidio una nota al final del capítulo correspondiente al suicidio anómico, así como algunos comentarios breves y dispersos. Lejos de una exposición explícita y sistemática, habremos de inferir la relación entre ambos de las similitudes que comparten, así como de sus más obvias diferencias. Y, sin duda alguna, lo que se infiere de esta comparación es que el rasgo subyacente a esta dimensión de la cohesión social, denominada por Durkheim regulación, es el "poder". No es casual, por tanto, que Durkheim inicie el capítulo del suicidio anómico con un breve párrafo en el que señala el ámbito en el que van a desplegarse los argumentos, en comparación al ámbito de la realidad social que sirvió de base para tratar los suicidios egoísta y altruista. Comienza diciendo: "Pero la sociedad no es solamente un objeto que atraiga, con una intensidad desigual, los sentimientos y la actividad de los individuos. Es también un poder que los regula" (Durkheim, 1998: 255). Es decir, la sociedad, frente al individuo, no sólo se despliega en la dialéctica comunicativa de la identidad, sino también en la dialéctica interactiva del poder, la fuerza y la coacción. No sólo atrae al individuo mediante la fusión de las conciencias,

\footnotetext{
${ }^{9}$ La cursiva es nuestra.
} 
RIS

RETISTA INTERNACIONAL DE SOCIOLOGIA

Na 28. Enero-tbril. 2001

EDUARDO BERICAT ALASTUEY

también los determina en tanto poder coactivo exterior. En este ámbito, no nos enfrentamos al dilema de la identidad o de la diferencia simbólica entre la sociedad y el individuo, sino al dilema de actividad, o práctico, que se despliega entre la voluntad individual y el poder social. Si podemos entender el poder, tal y como lo definió Weber, como "la probabilidad de imponer la propia voluntad, dentro de una relación social, aún contra toda resistencia y cualquiera que sea el fundamento de esta probabilidad" (Weber, 1979:43), es obvio que en cualquier relación que se establezca entre el sujeto y el mundo existen dos posibilidades. $\mathrm{O}$ bien el individuo es capaz de imponer su voluntad sobre los elementos del medio exterior, o bien el medio exterior, sea natural o social, determina y constriñe esa voluntad por medio de la aplicación de energía o del ejercicio de su poder. En la terminología weberiana, en el primer caso estaremos ante un sujeto autónomo, que se determina a sí mismo y controla el ambiente exterior siguiendo las propensiones de su voluntad. En el segundo, por el contrario, estaremos ante un sujeto heterónomo, incapaz de imponer su voluntad y determinado por fuerzas exteriores a él.

La descripción que ofrece Durkheim del suicidio fatalista, aunque breve, no deja lugar a dudas acerca de la relación de poder sobre la que se asienta: "Es el que resulta de un exceso de reglamentación: el que cometen los sujetos cuyo porvenir está implacablemente limitado, cuyas pasiones están violentamente comprimidas por una disciplina opresiva $[\ldots]$ ¿No se relacionan con este tipo los suicidios de esclavos, que se dice son frecuentes en estas condiciones, y todos los que, en una palabra, pueden ser atribuidos a las intemperancias del despotismo material o moral? Para mostrar claramente el carácter inflexible de la regla, contra la que nada se puede, y por oposiçión a esta expresión de anomia, que acabamos de emplear, podría llamársele el suicidio fatalista" (Durkheim, 1998:301). Esta definición corresponde, por tanto, al acto suicida determinado por una situación de completa y absoluta heteronomía, en la que la voluntad del sujeto, así como las actividades en las que potencialmente pudiera desplegarse, es incapaz de contrarrestar ninguna fuerza exterior, y menos aún el despotismo natural o social que se le impone. El sujeto nada puede, sus pasiones están "violentamente" comprimidas por una disciplina "opresiva", y las normas resultan ser inevitables e inflexibles. No cabe duda de que, en esta situación, la voluntad de sujeto, en tanto proyecto de actividad orientado a la propia satisfacción, está anulada por completo, y de ahí la referencia al porvenir implacablemente limitado. El ser humano, en tanto yo autónomo y activo, se proyecta sobre el mundo exterior con el objeto de controlar sus elementos y disponerlos, incluso contra su resistencia, en el sentido de la satisfacción de sus deseos. Pero este proyecto es arruinado en la situación fatalista. Bien sea porque a la voluntad se le antepone la fuerza coactiva del "poder social", bien sea porque se le anteponen "energías naturales" a las que es incapaz de doblegar, el ser humano que se divisa desde esta perspectiva es un ser impotente que no 
dispone, en absoluto, de los medios necesarios para llevar a cabo su proyecto personal frente a la actividad del mundo. Un sujeto que nada puede hacer y que, por tanto, nada puede querer.

En algunos otros comentarios, Durkheim refiere el malestar de esta impotencia. "Si como hemos señalado, los esposos demasiado jóvenes se matan mucho más que los célibes de la misma edad, es, sin duda, porque sus pasiones son entonces demasiado tumultuosas y demasiado confinadas en sí mismas para poder someterse a una regla [la matrimonial] tan severa. Esta les parece como un obstáculo insoportable, contra el que sus deseos vienen a chocar y romperse" (Durkheim, 1998:299-300). En otro lugar señala: "Una reglamentación tan estrecha como la del matrimonio, $\mathrm{y}$, sobre todo, del matrimonio monogámico no le es pues necesaria [a la mujer]. Ahora bien, tal disciplina, aún donde es útil, no deja de tener inconvenientes. Al fijar para siempre la condición conyugal, impide salir de ella suceda lo que suceda. Al limitar el horizonte cierra las salidas y corta todas las esperanzas, aún las legítimas. El hombre mismo [el varón] no deja de sufrir con esta inmutabilidad; pero le está ampliamente recompensado el mal con los beneficios que obtiene por otro lado" (Durkheim, 1998:296). Este párrafo tiene mucho interés, y no tanto porque señala los inconvenientes así como la insoportabilidad de los obstáculos insalvables al deseo (salvo, naturalmente, que este deseo no exista), sino porque relaciona el fatalismo con la imposibilidad de cualquier deseo y de toda esperanza. La absoluta constricción a la que está sometido el sujeto hace que, incluso el despertar del más pequeño de los deseos, la más insignificante chispa de la voluntad, esté abocada a la frustración y al dolor: "si [las necesidades] exigen más de lo que se les puede conceder, estarán contrariadas sin cesar y no podrán funcionar sin dolor. Ahora bien: un movimiento que no puede producirse sin sufrimiento tiende a no reproducirse" (Durkheim, 1998:262). En la situación fatalista, como hemos dicho, cualquier pequeño deseo, ante la ausencia completa de poder y ante la completa falta de medios, conduce al miedo y a la frustración. Tiene siempre por consecuencia la represión de los deseos y la anulación forzada de la voluntad, de modo que el movimiento vital tiende a no reproducirse. En el despotismo social o político, por ejemplo, cualquier aspiración se enfrenta a una represión, y de ahí el sentimiento de miedo. Y este miedo, cercenando todo deseo, es el que mantiene la frustración en un estado latente, es el que contiene la cólera de los esclavos. La voluntad, por temor, ni se excita ni se expresa. Su acción conduciría siempre a una reacción del exterior, aún más poderosa, que sin duda le provocaría un profundo dolor.

Lo que define esencialmente al contexto fatalista, como acabamos de ver, es el desequilibrio de poderes, la incapacidad del sujeto para doblegar al mundo según su voluntad. Cuál sea la naturaleza de los obstáculos que se le imponen a la voluntad es una cuestión secundaria. Sea un límite que proceda de su mundo personal, tal como una minusvalía física, sea uno que proceda del mundo natural, 
RIS

RETISTA INTERNACIONAL DE SOCIOLOGIS

tal como una catástrofe que lo lleva a la ruina, o uno que proceda del mundo social, como el despotismo que esclaviza, todos tendrán sobre la voluntad efectos parecidos, pues todos corresponden a fuerzas esencialmente exteriores al yo que privan a éste de su capacidad para controlar el mundo. Sin embargo, las coerciones sociales establecidas por las normas sociales presentan una radical ambigüedad que hace más difícil su comprensión. De hecho, el mismo Durkheim mantiene la confusión a lo largo de toda su obra, y esto porque tiende a identificar "orden social" con "orden moral". La ambigüedad de las normas deriva de su doble constitución. Por una parte son expresiones comunicativas explícitas, pero por otra hacen siempre referencia a alguna actividad (por ejemplo, "no matarás"). Esto es, "dicen" algo acerca de "hacer" o no hacer algo. Al mismo tiempo, por un lado hemos de considerar a las normas como productos de los procesos intercomunicativos que están en la base de la constitución dęl orden moral. Sin embargo, por otro lado, una vez establecidas, las normas adquieren el respaldo del poder social. Una norma constituye, desde este punto de vista, un proyecto coactivo de reacción social y, por tanto, sólo puede ser considerada norma en la medida que sus preceptos estén asociados a expectativas del uso de la fuerza o poder social. A efectos del análisis sociológico, estas matizaciones son fundamentales. Si la norma prohibe la homosexualidad, a una acción, esto es, al mantenimiento de relaciones sexuales de este tipo, corresponde una reacción, por ejemplo, la cárcel o la muerte, según los casos. Igual sucede con el robo. La clave es que a una "acción" corresponde una "reacción": si tú haces algo, la sociedad te hará algo a ti. Otra cosa muy distinta es cuando la homosexualidad no está bien vista, o se considera simplemente inmoral. En estos casos, a la acción no corresponde una reacción de fuerza, sino una reacción comunicativa. La clave es la siguiente: si tú haces algo, yo te podré decir algo. Podré insultarte, criticarte, despreciarte, etc., pero no podré hacer uso de la violencia contra ti. Así pues, las normas sociales, para ser propiamente normas, han de estar respaldadas por la coacción física. Y por muy morales o legítimas que sean, siempre anteponen al individuo un horizonte de coacción. Esto no significa que los consensos culturales, religiosos o morales, por el hecho de ser comunicativos carezcan de fuerza, eficacia o virtud. Si así fuera, ¿cómo podrían causar, según vimos en el suicidio altruista, incluso la muerte de los sujetos? Pero esta fuerza, la que proviene de la vergüenza o del orgullo, anida en el interior, y es producto de la identificación simbólica entre la conciencia del individuo y la conciencia social. La fuerza de la norma, al contrario, procede del exterior y, como todo límite exterior a la voluntad, provoca miedo, ira o frustración, pero nunca ni orgullo ni vergüenza (Kemper, 1978).

En suma, unas normas sociales inflexibles e inevitables, típicas de la situación fatalista, arruinan la voluntad del sujeto, y por derivación al sujeto mismo, al yo activo que subyace a todo sujeto con vida. El individuo se convierte así en un ser completamente heterónomo, dominado por fuerzas exteriores que no sólo 


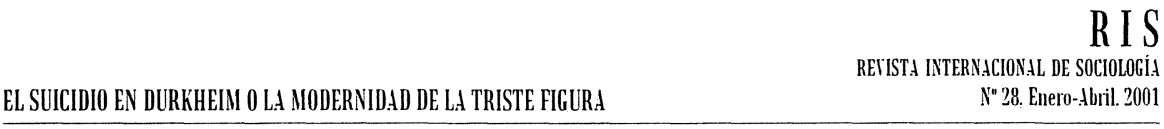

constriñen su conducta, sino que también limitan sus deseos. Se convierte en un ser sometido por el miedo a las reacciones exteriores y sometido por el miedo a la frustración. El "yo activo", establecido en términos de voluntad de control sobre el mundo, lo que implica capacidad para modificar ese mundo y capacidad para desear algo en el contexto de ese mismo mundo, desaparece bajo las aguas de las constricciones naturales y de la coacción social. No ha de extrañarnos, por tanto, que en este contexto en el que el yo activo desaparece, se incrementen los actos suicidas. Desde el punto de vista de la sociedad, es obvio que podremos observar mayores grados de cohesión social, pues la actividad de los miembros se ajustará perfectamente a los preceptos sociales. Sin embargo, se trata de una cohesión instituida desde el exterior por la fuerza, lo que sin duda causa una profunda frustración en el yo activo de los seres humanos, y establece un orden social inestable ubicado fuera del punto de equilibrio. En la medida que desaparezca o ceda la fuerza que se aplica, el orden se tambalea.

Es precisamente la naturaleza de este yo activo lo que subyace a la filosofia de la felicidad de Durkheim al estudiar los suicidios anómico y fatalista. En esta filosofia podemos encontrar tres elementos fundamentales que están en la base de su argumentación: a) la voluntad, los deseos o las aspiraciones de los seres humanos; b) la capacidad que tienen en un determinado contexto para realizarla, es decir, los medios o el poder de que disponen en relación con su entorno; y c) los logros efectivamente alcanzados, es decir, las modificaciones del mundo acordes con los contenidos de su voluntad. La felicidad, como ya indicara Epicuro, y siglos más tarde Schopenhauer, es relativa, pues está en función no de aquello que se obtiene en términos absolutos, sino de la ecuación individual entre aspiraciones y logros. La fortuna, nos dice Schopenhauer, "considerada en sí misma, está tan desprovista de sentido como el numerador de una fracción sin denominador" (Schopenhauer, 1984:81). Así mismo, Durkheim sentencia que "un ser vivo cualquiera no puede ser feliz, y hasta no puede vivir, a menos que sus necesidades estén en relación con sus medios" (Durkheim, 1998:262). En suma, aspiraciones, medios y logros constituyen el triángulo de una teoría de la frustración que explica tanto el suicidio fatalista como el anómico. En el primero, incluso con aspiraciones mínimas, según hemos comentado, se provoca la frustración por la carencia absoluta de medios, si bien esta frustración puede permanecer en estado latente debido a la propia anulación del deseo ${ }^{10}$. En el segundo, como veremos a partir de ahora, la frustración no emerge de una carencia de medios, sino de un desbordamiento de los deseos o de las

\footnotetext{
${ }^{10}$ Anulación que en la filosofia de Schopenhauer lleva a cabo el mismo individuo, pero que en la filosofia de Durkheim debe llevar a cabo la sociedad como poder moral que se le impone. El primero habla de autocontención, mientras el segundo de contención social de los deseos.
} 
R I S

RETISTA INTERNACIONAL DE SOCIOLOCIA-

N" 28, Enero-Abril. 2001

EDUARDO BERICAT ALISTUEY

aspiraciones que sobreexcitan la voluntad de los individuos. Para Durkheim, el punto óptimo es un equilibrado balance, no una perfecta equivalencia, entre las aspiraciones y los medios. Las aspiraciones posibles estimulan al yo activo en la lucha con el exterior, al tiempo que compensan con algunas satisfacciones vinculadas a los logros. En este sentido, rechaza tanto las aspiraciones imposibles, como la ausencia de cualquier aspiración. De ambos casos extremos siempre resulta dolor y tormento para el individuo, triste condena a la frustración.

En el orden socioeconómico, que regula las relaciones de los esfuerzos o trabajos (actividad) y los logros obtenidos (satisfacción), Durkheim observa preocupado la decadencia de los controles normativos instituidos en este ámbito por la sociedad tradicional. Observa cómo la religión, que consolaba a los trabajadores enseñándoles a contentarse con su suerte, y moderaba el afán de ganancia de los patronos recordándoles la vanidad de los intereses terrenales, ha perdido predicamento. Por otra parte, el poder político de la modernidad, antes que limitar las metas de bienestar material, elimina cuantas normas impidan la consecución de este objetivo, estableciendo los logros materiales como única medida de su legitimidad. Por último, el orden económico moderno, deja de autorregularse, como hicieran las corporaciones medievales y los gremios por medio de la fijación de precios, la limitación de los mercados y otras normativas similares. En suma, la decadencia de las regulaciones tradicionales (en la religión, en la política y en la economía) tiene por consecuencia el desbocamiento de los deseos y aspiraciones y, por tanto, el incremento de la frustración.

Sin embargo, para Durkheim, no es sólo esta condición negativa, esto es, la desaparición de las normas reguladoras, la que está atizando la voluntad y el deseo en la sociedad moderna. Es la propia sociedad moderna la que se constituye, positivamente, en tanto frustración al encumbrar los valores de progreso material al olimpo de sus dioses más queridos. Con cierta amargura, Durkheim señala el cambio: "entonces ha ocurrido que los apetitos que pone en juego se han encontrados libertados de toda autoridad que los limite. Esta apoteosis del bienestar, al santificarlos, por decirlo así, los ha puesto por encima de toda ley humana. Parece que hay una especie de sacrilegio en ponerles diques" (Durkheim, 1998:274). Y si esta sociedad se ocupa de mantener siempre las aspiraciones por encima de las realizaciones de los hombres (Merton, 1964), la sociedad moderna resulta ser la causa de un sentimiento, cada vez más extendido e intenso, de frustración. Una emoción que es social, también en este caso, no sólo atendiendo a su etiología, sino atendiendo a la extensión de sus efectos. En mayor o menor medida todos los individuos de la sociedad moderna están condenados a una perpetua frustración. La adquisición de bienes, o la mejora económica, nada puede hacer para paliar esta otra cara de la triste figura de la modernidad. Mucho antes de que llegue la satisfacción de un deseo, están ya dispuestos en fila otros tantos, en espera del momento oportuno para activar al individuo. Una especie de fatal rueda de la fortuna que, si bien otorga 
satisfacciones pasajeras, colmándonos de bienes, lo hace a costa de una casi eterna insatisfacción. No hay tiempo, nos dice Durkheim, para degustar lo conseguido ni para el tranquilo disfrute de lo que ya se posee, porque lo que falta por conseguir enseguida toma cuerpo en tanto carencia y, así, en tanto tristeza o ilusión desesperada. La imposibilidad de fijarse en el objeto conseguido, hace que el objeto de nuestro deseo esté siempre más allá, en un futuro alcanzable pero todavía no alcanzado.

Por estas razones, Durkheim entiende que "la anomia es, pues, en nuestras sociedades modernas, un factor regular y específico de suicidios" (Durkheim, 1998:277). La fe en el progreso, el futuro como realidad, el presente como proyecto, el desprecio de lo que se tiene, el valor de lo que se carece, elevando las aspiraciones del hombre moderno instituye poderosas fuerzas motivacionales orientadas a la actividad, al trabajo, al esfuerzo, al dominio y al control del mundo, claves de la sociedad moderna y capitalista. Al mismo tiempo, sin embargo, nos hace vivir en una continua y perpetua frustración. Pero la sociedad moderna no es sólo frustración, sino también logros e incremento del control sobre el mundo. $Y$ es precisamente esta realización continua de la voluntad la que genera una idea de la infinitud del poder del ser humano. Es precisamente la interiorización del éxito, la desaparición del fracaso en el horizonte mental del hombre, la que puede dar lugar a los mayores y más profundos desengaños. Es esta sensación de infinitud, este enseñoreamiento del hombre el que, en opinión de Durkheim, está detrás de todos los suicidios anómicos. "Ya sea progresiva o regresiva, la anomia, al franquear las necesidades de la medida que conviene, abre las puertas a las ilusiones, y, por consiguiente, a las decepciones. Un hombre que es bruscamente arrojado por debajo de la condición a la que estaba acostumbrado, no puede dejar de exasperarse al sentir escapársele una situación de la que se creía dueño" (Durkheim, 1998:311). Vemos así que, en la anomia regresiva, la persona pierde aquello a lo que ya creía tener derecho y nunca imaginó perder. Orientando su mirada hacia un futuro siempre mejorable, el choque con un futuro peor se le hace insoportable, pues la distancia entre el deseo y la realidad aumenta bruscamente. Y esta distancia se instituye como prueba irrefutable de la pérdida de control, el más íntimo y profundo deseo de la modernidad (Bauman, 1991).

Pero hay otros tipos de suicidio anómico. En la anomia progresiva, "el individuo es, por el contrario, arrastrado, pero sin regla ni medida, a sobrepasarse perpetuamente a sí mismo" (Durkheim, 1998:312). Tan pronto como un límite u obstáculo, por pequeño que sea, se interpone en esta frenética carrera del éxito, en esta confianza absoluta en el logro de cualquier meta que se propone el hombre, la frustración aparece. Éste es el suicidio del artista o del hombre de éxito que ya no concibe en su horizonte ningún fracaso, que llega a creerse omnipotente y que, por tanto, cualquier contrariedad le exaspera y desespera. Otro tipo de suicidio anómico procede del puro desasosiego que produce la 
continua persecución de metas futuras. El hecho de tener metas, la búsqueda de éxitos, se configura como la única meta concebible, de modo que el hombre deja de otorgar valor a aquello que consigue. Nada tiene valor concreto, lo único que vale es el avance, la consecución de metas, la continua sensación de logro, no la satisfacción de lo que se logra. Y esto, en opinión de Durkheim, no sólo conduce al desasosiego y a la fatiga crónica, sino también al vaciamiento del vínculo entre esfuerzo y objeto de satisfacción, es decir, a una absoluta pérdida de los criterios que podrían distinguir entre las cosas que merecen la pena ser conseguidas y las que no. Dicho con las muy gráficas palabras de Durkheim, nos encontramos ante "una persecución sin defensa posible". La voluntad de poder por el poder, del control por el control, del dominio por el dominio. Es la tristeza que acompaña al padre que ha gastado toda su vida trabajando y sólo al final de sus días se pregunta ¿para qué?.

En suma, todos los suicidios anómicos surgen del pensamiento moderno de que el hombre no tiene límites, del progreso material establecido como meta suprema, y de la voluntad omnímoda de control y de dominio sobre el mundo. Este conjunto de factores, que elevan la motivación para soportar el sacrificio con el que se han obtenido indudables logros, sólo puede estar cimentado en una continua frustración, causa próxima de este tipo de suicidios ${ }^{11}$. El desbordamiento de la voluntad, la sobreexcitación de los deseos, el dilema entre el infinito poder y la finita disponibilidad real, es lo que contribuye a este paradójico clima emocional en el que el éxito nunca puede ser garantía de satisfacción ni de felicidad, nunca llega a colmar la voracidad despertada en el ser humano. Es por esto que Durkheim vincula el suicidio anómico al estado emocional de la cólera, reflejando así la teoría que asocia la frustración a la ira o a la agresión. En este marco donde el deseo se absolutiza, y donde todo límite es visto como una constricción exterior, el hombre decepcionado se vuelve contra la causa que le impide seguir confiando y creyendo en su infinitud. Sobre ella descarga la ira, sea esta causa una persona, una situación, el mundo, la vida en general o hasta sí mismo. De ahí que Durkheim opte por la contención, y conciba la normas

\footnotetext{
"Mientras que Durkheim estudia los estados sociales que llevan a la frustración, Merton (1964:131-201), avanzando un paso más en el análisis, estudió también distintos tipos de conductas desviadas en tanto estrategias de los individuos para afrontar la frustración. En Merton, el modelo de frustración, o diferencia entre aspiraciones y logros, deriva socialmente del contraste entre la uniformidad social de la cultura del éxito y el acceso diferencial a recursos o medios legitimos vinculados específicamente a diversas posiciones en la estructura social. Asi pues, Merton añade al estudio de las causas sociales de la frustración, el estudio de sus efectos o consecuencias sociales. En este sentido, supera y especifica el simple modelo de frustración-agresión utilizado por Durkheim.
} 
sociales como un instrumento idóneo para moderar las ilimitadas aspiraciones del hombre moderno. En su perspectiva, cualquier limitación de las aspiraciones reducirá la tasa de suicidios. Así se manifiesta al hablar de la pobreza y de la miseria como un antídoto del suicidio. El hombre no se suicida por la dureza de la vida, pues estando acostumbrado a ella, está acostumbrado también a no esperar demasiado de la vida. Y esta contención de las aspiraciones vale tanto para el orden económico como para el orden sexual, esto es, tanto para el tratamiento de la anomia económica como para el de la anomia conyugal. Sabido es que Durkheim estaba francamente en contra de las leyes del divorcio. La virtud del matrimonio, que no es otra cosa que una reglamentación de las relaciones entre los sexos, estriba en que define el objeto del deseo, lo limita y, al mismo tiempo, ofrece los medios de su satisfacción. "Si sus goces están definidos, también están asegurados, y esta certidumbre consolida su consistencia mental. Completamente distinta es la situación del célibe. Como puede legitimamente ligarse a lo que le plazca, aspira a todo y nada le satisface. Este mal del infinito que la anomia lleva consigo por todas partes, puede alcanzar lo mismo esta zona de la conciencia que cualquier otra" (Durkheim, 1998:294). Y este mismo estado es el que se potencia cuando existen leyes de divorcio, cuando el ser humano no está sometido a limitación y determinación de sus objetos de deseo.

Las normas, por tanto, en la concepción de Durkheim, no sólo contribuyen a la cohesión social, sino que también son necesarias para la felicidad de los individuos. Estas normas funcionan como límites a los insaciables apetitos del ser humano, bien procedan de su naturaleza orgánica, como en el caso del deseo sexual de los jóvenes, bien procedan de una causa social, como en el caso de la sociedad moderna ${ }^{12}$. Desde la teoría de la anomia, Durkheim justifica la presencia de un poder social, de carácter normativo, que contenga, modere y determine los insaciables apetitos individuales. Un poder social que debe ser también un poder moral, pues las normas no sólo han de ser coactivas, sino además justas, no sólo deben inspirar miedo, sino además respeto ${ }^{13}$.

\footnotetext{
${ }^{12}$ Durkheim alterna, según conviene a sus argumentos, estos dos origenes de la ilimitud. Unas veces se atribuye a la naturaleza de su ser orgánico en tanto afectada por una espiritualidad capaz de concebir deseos infinitos. Otras, estos deseos infinitos son directamente estimulados por la naturaleza propia de la sociedad moderna. En cualquier caso, concibe al hombre como un ser insatisfecho, dominado por apetitos insaciables. No es necesario advertir que con ello se aleja de la pura interpretación social del ser humano.

${ }^{13} \mathrm{La}$ orientación socialmente conservadora de Durkheim, frente a Marx, se pone de manifiesto en el hecho de que el primero cree posible una sociedad ordenada y desigualitaria, en la que sus miembros ocupen posiciones sociales funcionalmente diferentes, y reciban, por tanto, recompensas desiguales. Para Durkheim, la clave de esta posibilidad estaba en la limitación normativa de las aspiraciones de quienes ocupaban las distintas posiciones en la división social del trabajo.
} 


\section{CONCLUSIONES}

La teoría del suicidio de Durkheim pone de relieve las relaciones existentes entre cohesión social y afecciones colectivas. En concreto, vincula los polos opuestos de las dos dimensiones básicas de la cohesión social, la integración y la regulación, con los climas emocionales de la sociedad y con los estados afectivos de sus miembros individuales. En la medida que la intención auténtica de Durkheim era señalar aquellos aspectos negativos implícitos en el proceso de modernización, así como en la modernidad misma, concede más importancia en su estudio a los polos individualista y anómico de las dimensiones de cohesión social. Lo importante, sin embargo, es que en tanto sociólogo estableció conexiones plausibles, a través del análisis de tasas sociales de suicidio, entre rasgos colectivos de una sociedad y emociones de sus miembros. De ahí que su teoría esté sustentada sobre sendas filosofias de la felicidad que otorgan sentido científico y sentido práctico a su gran obra. La primera clasificación de suicidios, la que distingue entre los suicidios egoísta y altruista, señala que la felicidad del ser humano se encuentra en un punto medio, o de equilibrio ${ }^{14}$, entre la conciencia individual y la conciencia colectiva, el punto en el que la conciencia de la persona se constituye simultáneamente en tanto unidad y diferencia con la conciencia colectiva. La identidad de la persona sólo puede constituirse en tanto reflejo, pero reflejo diferenciado, distorsionado y singular del espejo social. Una identidad absoluta con el grupo borra la conciencia del yo; un alejamiento excesivo del espejo impide la formación de cualquier identidad. La segunda clasificación, la que distingue entre los suicidios anómico y fatalista, señala que la felicidad sólo puede encontrarse en un punto medio, o de equilibrio, entre la autonomía y la heteronomía. Un ser humano que no puede hacer nada frente a

Esto no sería posible por medio de la pura coacción, sino por medio de la coacción de un poder moral asociado a una justa distribución del producto social. Ver Durkheim (1998:267-9). Para una exposición del conservadurismo de Durkheim en relación al conflicto de clases, ver Zeitlin (1979:306-11).

${ }^{14}$ En este aspecto, puede considerarse a Durkheim continuador sociológico de la tradición aristotélica del justo término, o punto medio, entre dos extremos que señalan el exceso o defecto de alguna cualidad o estado necesario para el establecimiento de una buena vida. En contra de Besnard (1998), no creo que Durkheim abandonara definitivamente ese aspecto de su teoria. Besnard piensa que sustituyó el "modelo del punto medio", por el "modelo de fuerzas en equilibrio". En mi opinión, el error de Besnard se debe a que no distingue bien las fuentes de las dos clasificaciones de tipos de suicidio, como hemos visto, soportada una sobre la dimensión intercomunicativa, y otra sobre la dimensión interactiva. Mientras que en la conciencia no pueden darse oposición entre fuerzas, en la actividad si se dan, pues toda actividad está sustentada sobre algún tipo de energía. Esto explica que sólo en la distinción de suicidios anomico-fatalista se observe un modelo de equilibrio de fuerzas. Pero este equilibrio de fuerzas es también una traducción de la filosofia del punto medio. 
su entorno, incapaz de modificar el contexto en función de su voluntad, puede considerarse un ser muerto. A la inversa, un ser humano que no reconoce al entorno, que se cree capaz de moldear el mundo a su antojo, y que no acepta algunos límites a su voluntad, se consume en la vana e interminable tarea de controlar el mundo y muere para sí. En ambos casos, la infelicidad se demuestra por la presencia de algunas emociones. En un caso la depresión y la vergüenza; en otro la frustración y la ira. En suma, Durkheim proyecta con su estudio del suicidio una sociedad en la que el yo comunicativo, en busca de una identidad integrada en la cultura social, y el yo activo, en busca de una voluntad compatible con el poder social, encuentren la armonía necesaria, sustento de la felicidad.

La obra de Durkheim es el ejemplo más claro y coherente de la doble constitución del orden social, un orden que sólo es logrado en la fusión simbiótica de la dimensión intercomunicativa y de la dimensión interactiva de la sociabilidad del ser humano. Orden que pueden convertirse en caos social cuando con esta trama y esta urdimbre de la interacción no logra confeccionarse un tupido tejido social en el que tanto la conciencia como la actividad se sustentan mutuamente. No distinguir entre las dos dimensiones de la cohesión, por un lado, y la distintiva realidad del orden/caos social, por otro, ha generado no pocas confusiones y malentendidos a la hora de interpretar correctamente la obra de Durkheim ${ }^{15}$. En concreto, no se ha entendido bien que Durkheim alude a tres afecciones colectivas o estados de malestar que provoca la sociedad moderna, y se ha tendido a confundir el tercero como un tipo especial de anomia, del que no ha podido distinguirse con claridad ${ }^{16}$. La anomia, tal y como se ha

\footnotetext{
${ }^{15}$ Un caso notorio de flagrante error puede verse en Aron (1980:43), donde confunde el sucidio egoísta con el anómico: "Toda situación que tienda a aumentar la disparidad entre los deseos y la satisfacción se expresa en un coeficiente de agravamiento. Este primer tipo social de suicidio, establecido mediante el estudio estadístico de las correlaciones, se define con el término egoísmo". Es obvio que la frustración que indica Aron constituye elemento esencial del suicidio anómico, no del egoísta. Esto pone de relieve la importancia de especificar las emociones asociadas a cada tipo de suicidio para comprender la verdadera naturaleza de las dimensiones integradora y reguladora de la cohesión social. Sin esta especificación emocional, como sucede en otros muchos autores, las distinciones se dibujan sobre un telón de fondo de ambigüedad.

${ }^{16}$ En la mayor parte de la interpretaciones de El suicidio está más o menos presente, aunque irresuelto, el tema de las dos anomias. Aqui proponemos una solución tentativa, prefiriendo restringir el concepto de anomia al estado social caracterizado, exclusivamente, por una falta de normas que afectan al triángulo formado por la voluntad, la actividad y la satisfacción. O si se quiere, por las aspiraciones, los medios y los logros. El problema de la confusión con el tercer malestar deriva de que la interactividad es también constituyente del orden social. En nuestra opinión, sin embargo, debe y puede distinguirse la naturaleza y el poder constituyente de la interactividad, así como el de la intercomunicación, de la naturaleza propia, especifica y peculiar del orden/caos social.
} 


\section{RIS}

expuesto en el epígrafe anterior, hace alusión a los efectos negativos que un déficit de constricción normativa tiene sobre los individuos y sobre la propia sociedad. Este concepto, en sentido estricto, está asociado a la dimensión interactiva del ser humano, aquélla que lo contempla como un ser activo que necesariamente ejerce su voluntad frente al mundo. Sin embargo, hay otro concepto, el de caos social, que expresa mucho mejor el tercer malestar al que se refiere Durkheim en muchas ocasiones. El estado de caos, como opuesto al de orden, se produce cuando el yo comunicativo y el yo activo dejan de constituirse sobre la base de un mundo estable y regular, y sobre la base de una coincidencia entre las expectativas de los seres humanos y la realidad del mundo en el que viven. En este estado de caos, además, el yo comunicativo y el yo activo ya no están armónicamente integrados, ya no se confirman ni verifican mutuamente, por lo que el sentido de la realidad se resquebraja. La sensación de pérdida y de vacío puede llegar a ser total. La identidad del yo no puede autoconstituirse en la conciencia porque los símbolos de su universo han perdido tanto su significado como su sentido. Por otra parte, la voluntad del yo, que se sustenta sobre la tensión que ofrecen al individuo las resistencias que le presenta el mundo, pierde su orientación cuando la actividad del mundo modifica radicalmente su estructura de acción.

Un mundo social ordenado, en el que la armonía con el mundo natural y con el mundo personal subsiste, en el que cultura y actividad confluyen para conformar acciones humanas con sentido y al mismo tiempo eficaces, en el que identidad y voluntad se corresponden y verifican recíprocamente, es el que Durkheim añoraba al observar la magnitud y la rapidez de los cambios que llegaban con los procesos de modernización. Una sociedad moderna, caracterizada por ser una sociedad de cambio, en la que el cambio era la norma por excelencia, auguraba según Durkheim un perpetuo estado de caos social. Un caos social institucionalizado, pero caos social al fin y al cabo. Todo cambio social modifica el orden, un orden que sólo puede lograrse por una lenta adaptación que siempre requiere su tiempo. Cuando más rápido y cuanto más catastrófico sea el cambio, e independientemente de que la catástrofe sea positiva o negativa, en mayor medida aparece el caos, el desajuste y el vacío. En estos casos la sociedad no puede hacer nada para ayudar al individuo porque, hablando con rigor, o no hay sociedad en absoluto, o se encuentra mortalmente debilitada, sin fuerzas para ofrecer al ser humano un mundo. La ciencia, por el lado de la comunicación, y los medios de producción, por el lado de la actividad, se le antojaban a Durkheim como los grandes topos que estaban horadando el orden tradicional. No proyectaba sobre la ciencia ni sobre el afán de riquezas una culpa absoluta, pues creía que sólo ellas podrían llenar el vacío dejado por el debilitamiento de las creencias y de las reglamentaciones tradicionales. Pero era obvio que ambas metas, tanto el logro del conocimiento y como el desarrollo de la riqueza, implicaban una modificación continua de la imagen del mundo 
y de su estructura de fuerzas.

En suma, el hombre se enfrenta en virtud de la institucionalización del cambio por el desarrollo de la ciencia (cultura) y de la economía (trabajo), a un tercer sentimiento que se convierte en otro componente base del clima emocional de la modernidad. El hombre moderno está abocado a vivir en un crónico estado de sorpresa. Una sorpresa, una perplejidad e incertidumbre provocada por los continuos cambios del mundo natural, del mundo social y del mundo personal ${ }^{17}$. Nada permanece estable, por lo que el hombre debe permanecer alerta a las modificaciones de los tres mundos. El mundo de mañana será distinto al de hoy, y tanto las expectativas como la confianza que tengo hoy depositadas en este mundo de nada me servirán. Cada día me enfrentaré a la tarea de reconstruirme en un mundo nuevo. Mañana no podré reconocer al mundo, ni podré reconocerme a mí, y sin reconocimiento no puede existir confianza ${ }^{18}$ (Luhmann, 1996). Mi identidad y mi voluntad se verán radicalmente modificadas. Estaré condenado cada día a ser un distinto yo en un mundo diferente. Y lo peor, en opinión de Durkheim, es que un día no basta para generar el sentimiento de confianza vinculado a la felicidad. Un exceso de "sorpresa", entendiendo esta emoción en su sentido radical, no es buena a los ojos de Durkheim, como tampoco podrá serlo, si nos atenemos a su perspectiva filosófica general, un exceso de tedio. Una excesiva estabilidad, es decir, la constitución de un orden inmutable de identidades y de voluntades fijas, un mundo acaso configurado sobre el paradigma del eterno retorno, en el que nunca aparece nada nuevo bajo el sol, tampoco puede proporcionar el contexto adecuado para la felicidad.

\footnotetext{
${ }^{17}$ Un ejemplo reciente de los efectos de la flexibilidad que el cambio impone sobre el individuo, que atiende además a los efectos emocionales sobre las personas, puede verse en la obra de Richard Sennett (2000).

${ }^{18}$ Parsons tampoco distingue entre las condiciones específicas de la anomia, y las condiciones de caos social. Estas últimas están vinculadas a la sorpresa, la incertidumbre, la ansiedad, la desconfianza y la confusión. Parsons evidencia esta falta de definición al citar conjuntamente "la sensación de confusión y frustración" en las depresiones económicas (Parsons, 1968:422). La confusión forma parte del complejo emocional del caos, mientras que la frustración forma parte del complejo emocional de la anomia. El hecho es que en la realidad empírica pueden darse simultáneamente, pero esto no significa que constituyan un fenómeno idéntico. Así por ejemplo, en períodos de rápida bonanza económica los efectos de desajuste o caos se presentarán desde el principio. Sin embargo, la frustración sólo podrá presentarse una vez avanzado el proceso, es decir, cuando el incremento de posibilidades hayan disparado y generalizado las aspiraciones. En los inicios de bonanza económica el clima emocional suele ser de alegria e incluso de orgullo, pues los individuos obtienen los primeros objetos de deseo y se perciben como causa directa de las mejoras. Insistimos que el ser humano es una realidad dinámica, y esto hace que su conciencia emocional pueda ser tan distinta, incluso en periodos que con indicadores materiales, como la renta o su tasa de incremento, pudiéramos considerar uniformes u homogéneos.
} 
RIS

RETISTA INTERNACIONAL DE SOCIOLOGIA

No 20. Enero-dbril. 2001

EDUARDO BERICAT ALASTUEY

En este caso, la emoción de inabordable sorpresa de una sociedad en continuo cambio, sería sustituida por un inconmensurable tedio, por un aburrimiento vital derivado de la plena y total adaptación, carente de tensiones, entre el ser humano y el mundo. Nada que crear, ausencia total de novedad, por un lado; nada que repetir, imposibilidad del hábito, por el otro. Ambos extremos provocan en el ser humano, sin duda, una profunda ansiedad.

Nuevamente, Durkheim da la impresión de inclinarse por la estabilidad y por la existencia de orden, pero este sesgo, en mi opinión, se deriva de su interés por destacar aspectos del proceso de modernización apenas percibidos por algunos de sus contemporáneos. Frente al optimismo positivista moderno, basado en las ilusionadas perspectivas de la ciencia, de la riqueza y del progreso como horizonte utópico del cambio asociado al proceso de modernización, Durkheim quiso advertir que no existen dioses sin demonios, que la ciencia provocaría depresión, que la riqueza provocaría frustración, y que el progreso provocaría ansiedad. La advertencia de que la modernidad se poblaría de caballeros de la triste figura parece no haber servido de nada. Quizás ahora, a las puertas de la posmodernidad, sus advertencias estén adquiriendo un renovado vigor. De ahí la actualidad de su tesis.

\section{REFERENCIAS BIBLIOGRÁFICAS}

ALEXANDER, J. C. (1989), Durkheimian sociology: cultural studies, Cambridge University Press, New York.

ALVIRA MARTÍN, F. y F. BLANCO MORENO (1998), "Estrategia y técnicas investigadoras en El suicido, de Emile Durkheim", Revista Española de Investigaciones Sociológicas, $n^{\circ} 81$, pp. 63-72.

ARON, R. (1980), Las etapas del pensamiento sociológico, II, Buenos Aires, Siglo Veinte.

BAUMAN, Z. (1991), Modernity and ambivalence, Cambridge, Polity Press.

BERGER, P. L. y T. LUCKMANN (1997), Modernidad, pluralismo y crisis de sentido. La orientación del hombre en el mundo moderno, Barcelona, Paidós.

BERICAT ALASTUEY, E. (1998), La integración de los métodos cuantitativo y cualitativo en la investigación social. Significado y medida, Barcelona, Ariel.

(1999), "El contenido emocional de la comunicación en la sociedad del riesgo. Microanálisis del discurso", Revista Española de Investigaciones Sociológicas (REIS), nº 87, pp. 221-253.

(2000a), "La sociologia de la emoción y la emoción en la sociología", Papers. Revista de Sociología, $\mathrm{n}^{\circ} 62$, pp. 145-176. 
(2000 b), Idea de la sociología (mecanografiado), Departamento de Sociologia, Universidad de Málaga.

(2001), "Max Weber o el enigma emocional del origen del capitalismo", Revista Española de Investigaciones Sociológicas (REIS), $\mathrm{n}^{\circ} 95$.

BESNARD, F. (1998), "Anomia y fatalismo en la teoría durkheimiana de la regulación", Revista Española de Investigaciones Sociológicas, nº 81, pp. 41-62.

BUNGE, M. (1999), La relación entre la sociologia y la filosofia, Madrid, Edaf.

DURKHEIM, E. (1982), La división del trabajo social, Madrid, Akal.

(1993), Las formas elementales de la vida religiosa, Madrid, Alianza.

(1998), El suicidio, Madrid, Akal.

ELIAS, N. (1993), El proceso de la civilización. Investigaciones sociogenéticas y psicogenéticas, Madrid, F.C.E.

FREUD, S. (1975), El malestar en la cultura, Madrid, Alianza.

GIDDENS, A. (1977), El capitalismo y la moderna teoria social, Barcelona, Labor.

GODELIER, M. (1998), El enigma del don, Barcelona, Paidós.

HIRSCHMAN, A.O. (1999), Las pasiones y los intereses, Barcelona, Península.

HOCHSCHILD, A.R. (1983), The Managed Heart. Commercialization of Human Feeling, Berkeley, University of California Press.

KEMPER, Th. D. (1978), A Social Interactional Theory of Emotions, Nueva York, John Willey $\&$ Sons.

LUKMANN, N. (1996), Confianza, Barcelona, Anthropos.

MERTON, R. K. (1964), Teoría y estructura sociales, Buenos Aires, Fondo de Cultura Económica.

PARSONS, T. (1968), La estructura de la acción social I, Madrid, Guadarrama.

(1982), El sistema social, Madrid, Alianza.

RAMOS TORRE, R. (1998), "Un tótem frágil: aproximación a la estructura teórica de El suicidio", Revista Española de Investigaciones Sociológicas, $\mathrm{n}^{\circ} 81$, pp. 17-40.

RODRÍGUEZ IBÁÑEZ, J. E. (1999), "Laudatio de El suicidio, de Durkheim”, Papers. Revista de Sociología, n 57, pp. 33-38. 
RIS

REIISTA INTERNACIONAL DE SOCIOLOGI

Na 28. Enero-Aluril. 2001

EDUARIDO BERICAT ALASTUEI

SCHEFF, Th. J. (1988), "Shame and Conformity: The Deference-Emotion System", American Sociological Review, vol. 53, pp. 395-406.

(1990), Microsociology: Discourse, Emotion and Social Structure, Chicago, The University of Chicago Press.

(2000), "Shame and the social bond: A sociological theory", Sociological Theory, vol. $18, n^{\circ} 1$, pp. 84-99.

SCHOPENHAUER, A. (1984), La sabiduría de la vida, México, Porrúa.

SEMINARIO DE FUNDAMENTOS CLÁSICOS DE SOCIOLOGÍA (1999), "Centenario de El suicidio, de Émile Durkheim (1987-1997)", Papers. Revista de Sociologia, n 57, pp. 39-72.

SENNETT, R. (2000), La corrosión del carácter: Las consecuencias personales del trabajo en el nuevo capitalismo, Barcelona, Anagrama.

SMITH, A. (1997), La teoria de los sentimientos morales, Madrid, Alianza.

WEBER, M. (1998), Ensayos sobre sociologia de la religión, vol I, Madrid, Taurus.

WILLARD GAYLIN, M.D. (1989), The Rage Within. Anger in Modern Life, New York, Penguin.

ZEITLIN, I. (1979), Ideología y teoría sociológica, Buenos Aires, Amorrortu. 